\title{
Active Action Potential Propagation But Not Initiation in Thalamic Interneuron Dendrites
}

\author{
Amanda E. Casale and David A. McCormick \\ Department of Neurobiology, Kavli Institute for Neuroscience, Yale University School of Medicine, New Haven, Connecticut 06510
}

Inhibitory interneurons of the dorsal lateral geniculate nucleus of the thalamus modulate the activity of thalamocortical cells in response to excitatory input through the release of inhibitory neurotransmitter from both axons and dendrites. The exact mechanisms by which release can occur from dendrites are, however, not well understood. Recent experiments using calcium imaging have suggested that $\mathrm{Na} / \mathrm{K}$-based action potentials can evoke calcium transients in dendrites via local active conductances, making the backpropagating action potential a candidate for dendritic neurotransmitter release. In this study, we used high temporal and spatial resolution voltage-sensitive dye imaging to assess the characteristics of dendritic voltage deflections in response to $\mathrm{Na} / \mathrm{K}$ action potentials in interneurons of the mouse dorsal lateral geniculate nucleus. We found that trains or single action potentials elicited by somatic current injection or local synaptic stimulation rapidly and actively backpropagated throughout the entire dendritic arbor and into the fine filiform dendritic appendages known to release GABAergic vesicles. Action potentials always appeared first in the soma or proximal dendrite in response to somatic current injection or local synaptic stimulation, and the rapid backpropagation into the dendritic arbor depended upon voltage-gated sodium and tetraethylammonium chloride-sensitive potassium channels. Our results indicate that thalamic interneuron dendrites integrate synaptic inputs that initiate action potentials, most likely in the axon initial segment, that then backpropagate with high fidelity into the dendrites, resulting in a nearly synchronous release of GABA from both axonal and dendritic compartments.

\section{Introduction}

The most common site for neurotransmitter release between neurons is at synaptic terminals located along or at the ends of axons. However, there are a significant number of brain regions where transmitter release occurs from dendrites or dendritic appendages (for review, see Kennedy and Ehlers, 2011). Although axonal transmitter release has been extensively studied in the mammalian brain, dendritic transmitter release has been difficult to study, owing in part to the difficulty in obtaining electrical recordings from fine dendritic structures. The thalamus is one area were dendrodendritic synaptic transmission is prevalent and experimentally approachable.

In mammals, visual information is passed from the retina to the visual cortex mainly through the dorsal lateral geniculate nucleus of the thalamus (LGNd). In the LGNd, retinal ganglion cells form excitatory synapses onto thalamocortical cells, which in turn project to layer 4 of the visual cortex. Interestingly, only 5-10\% of terminals onto thalamocortical cells are from the retina, the primary sensory input to this region (Erişir et al., 1997b).

Received Aug. 25, 2011; revised 0ct. 7, 2011; accepted Nov. 1, 2011.

Author contributions: A.E.C. and D.A.M. designed research; A.E.C. performed research; A.E.C. analyzed data; A.E.C. and D.A.M. wrote the paper.

This work was supported by the NIH and the Kavli Institute for Neuroscience. We thank Amanda Foust, Robert Sachdev, and Markus Wolfel for reading and commenting on this manuscript; and Dejan Zecevic, Marko Popovic, and Amanda Foust for guidance on voltage-sensitive dye methodology. We also thank Tom Morse for expert assistance with NEURON.

Correspondence should be addressed to David A. McCormick, Kavli Institute for Neuroscience, Yale University School of Medicine, 333 Cedar Street, New Haven, CT 06510. E-mail: david.mccormick@yale.edu.

DOI:10.1523/JNEUROSCI.4417-11.2011

Copyright $\odot 2011$ the authors $\quad 0270-6474 / 11 / 3118289-14 \$ 15.00 / 0$
The remainder of contacts onto thalamocortical cells arises from brainstem, layer 6 of visual cortex, reticular thalamus, and intrathalamic inhibitory neurons. These nonretinal synapses are believed to play a role in shaping the response of thalamocortical cells to retinal input. Of particular importance are inhibitory (GABA) connections, formed by local circuit neurons onto proximal regions of thalamocortical dendrites. Inhibitory interneurons have been implicated in controlling the precise spike timing of thalamocortical cells to retinal excitation, and in refinement of thalamocortical receptive fields (Sillito and Kemp, 1983; Berardi and Morrone, 1984; Guillery and Sherman, 2002; Blitz and Regehr, 2005). Canonically, this inhibition would be accomplished by generation of an action potential in response to retinal input, which would propagate along the interneuron axon causing vesicular GABAergic release from axonal terminals onto thalamocortical dendrites. Thalamic interneurons, however, are unique in that they express GABAergic vesicles not only in axonal boutons, but also in dendritic appendages (Famiglietti, 1970; Famiglietti and Peters, 1972; Rafols and Valverde, 1973; Montero, 1986). A majority of interneuron synapses in the LGNd are made by these dendritic boutons. While axonal release is typically controlled by action potential propagation into terminal boutons, it is less certain whether action potentials can propagate completely throughout the interneuron dendritic arbor to promote vesicle release from dendritic appendages. Although calcium imaging experiments have suggested that $\mathrm{Na} / \mathrm{K}$ action potentials can propagate into the dendrites to promote calcium transients (Acuna-Goycolea et al., 2008), a direct measure of $\mathrm{Na} / \mathrm{K}$ action potentials in the interneuron dendrite has been precluded by the dendrite's fine caliber. 
In our study, we used a combination of high temporal and spatial resolution voltage-sensitive dye (VSD) imaging to demonstrate that trains of action potentials actively propagate throughout the entire interneuron dendrite and into dendritic appendages. Activation of tetrodotoxin (TTX)-sensitive $\mathrm{Na}^{+}$channels was necessary for dendritic action potential propagation, while tetraethylammonium chloride (TEA)-sensitive $\mathrm{K}^{+}$channels were important for dendritic action potential repolarization. Despite the active and reliable backpropagation of action potentials throughout the dendritic arbor, local synaptic inputs alone failed to initiate spikes in interneuron dendrites. Thus, the generation of an action potential in thalamic interneurons can result in a rapid and global inhibitory signal through the release of GABA from both axons as well as dendritic terminals.

\section{Materials and Methods}

Slice preparation and maintenance. We prepared coronal slices of mouse thalamus (LGNd) from GAD67-GFP mice (gift from Dr. Y. Yanagawa, Gunma University, Maebashi City, Japan) in accordance with national and institutional guidelines. Male or female mice (23-54 d old) were deeply anesthetized with sodium pentobarbital $(50 \mathrm{mg} / \mathrm{kg})$ and killed through decapitation. The brain was rapidly removed and placed in ice-cold $\left(<5^{\circ} \mathrm{C}\right)$ cutting solution containing the following (in mM): $2.5 \mathrm{KCl}, 1.2 \mathrm{NaH}_{2} \mathrm{PO}_{4}, 26 \mathrm{NaHCO}_{3}, 10$ dextrose, 215 sucrose, $2 \mathrm{MgSO}_{4}, 2 \mathrm{CaCl}_{2}$. Coronal slices, $250 \mu \mathrm{m}$ thick, were cut on a Leica microslicer in ice-cold cutting solution and transferred to a $35^{\circ} \mathrm{C}$ incubation chamber containing artificial CSF (in mM): 126 $\mathrm{NaCl}, 2.5 \mathrm{KCl}, 1.25 \mathrm{NaH}_{2} \mathrm{PO}_{4}, 26 \mathrm{NaHCO}_{3}, 25$ dextrose, $2 \mathrm{MgSO}_{4}, 2 \mathrm{CaCl}_{2}$. Slices were allowed to incubate for at least $1 \mathrm{~h}$ before dye loading and recording in a submersion chamber.

Cell selection. The voltage-sensitive dye imaging system is constructed around an upright microscope (BX51WI, Olympus) equipped to switch readily among the following three different imaging systems: (1) confocal epifluorescence for cell selection and morphological reconstruction (Yokogawa CSU-22, Solamere Technology); (2) infrared-differential interference contrast (IR-DIC) video microscopy for establishing whole-cell recordings; and (3) wide-field epifluorescence for voltage-sensitive dye imaging. Slices were initially examined with the confocal imaging system to determine morphological completeness of individual GFP-positive cells using an optically pumped semiconductor laser (Sapphire 488-20, Coherent). Suitable cells for wide-field voltage-sensitive dye imaging had intact dendritic arbors that were lying within a single focal plane located within $50 \mu \mathrm{m}$ of the slice surface. These criteria ensure that large portions of the dendritic arbor can be monitored simultaneously with minimal degradation of the image from light scattering in the tissue. The GFP fluorescence does not interfere with voltage-sensitive dye signals because of the nonoverlapping emission spectra of these two fluorophores.

Voltage-sensitive dye loading and recording. Suitable GFP-positive neurons were loaded with voltage dye through a glass patch electrode by filling the tip with dye-free internal solution (in mM: $130 \mathrm{~K}$-gluconate, 7 $\mathrm{KCl}, 4$ ATP-Mg, 0.3 GTP-Na, 10 phosphocreatine-Na, 10 HEPES, $0.4 \%$ biocytin, adjusted to $\mathrm{pH} 7.4$ and $284 \mathrm{mOsm}$ ) and backfilling with dyecontaining internal solution (JPW3028; 400-800 $\mu \mathrm{M}$ ), as pioneered earlier (Grinvald et al., 1987). The voltage-sensitive dye JPW3028 is a doubly positively charged analog of the aminostyryl-pyridinium series of lipo-
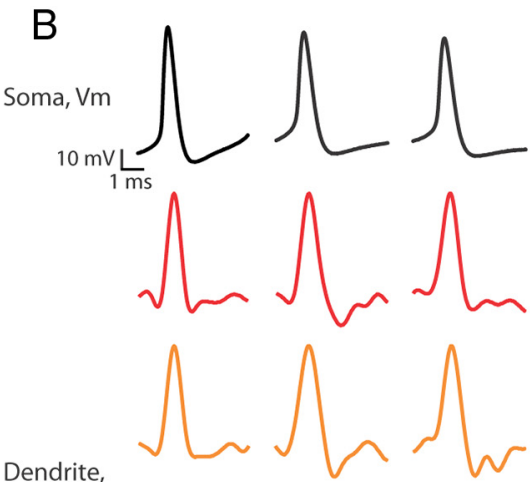

Dendrite Optical
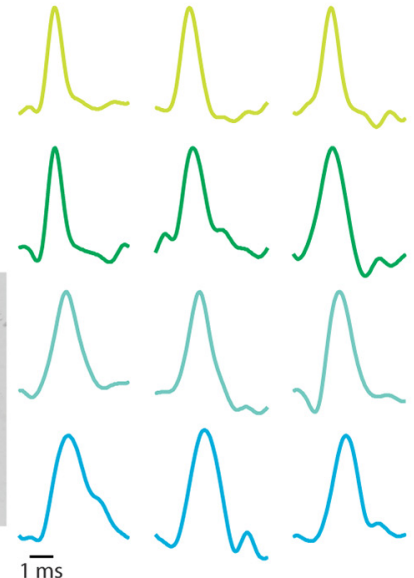

Average of 2 Trials, 3 Spikes per Trial (2 kHz VSD sample rate)

Figure 1. Action potentials propagate throughout the dendritic arbor. $\boldsymbol{A}$, Voltage-sensitive dye (VSD) fluorescence confocal corresponding to three action potentials in a train initiated by a depolarizing step at the soma. Electrical and optical signals are an average of two trials. Black traces are somatic electrode recordings. Colored traces are optical signals $(\Delta F / F)$ acquired at $2 \mathrm{kHz}$ in the dendrite. Colored traces correspond to colored boxed regions in $\boldsymbol{A}$. Optical traces are normalized to peak amplitude.

philic voltage-sensitive dyes that is available from Invitrogen as D-6923. This electrochromic dye does not significantly increase the membrane capacitance of the labeled neuron as evident from a number of control measurements showing that the waveform of the electrically recorded action potentials remains unaltered after intracellular application of the dye (Canepari et al., 2007; Foust et al., 2010). The physical basis for the lack of the capacitive load effect, characteristic for some fluorescence resonance energy transfer (e.g., dipicrylamine), as well as some protein voltage probes, is that the interaction of the electric field with electrochromic dyes leads to a charge movement across only a very small fraction of the membrane field (the size of the chromophore) (Blunck et al., 2005). Action potential waveform characteristics recorded electrically at the soma (10-90\% rise time, full-width at half-height, threshold, amplitude) were unchanged between dye-loaded and unloaded cells ( $p>0.05$, unpaired $t$ test; $n=13$ for each group). Dye-free solution in the tip of the patch electrode was necessary to prevent spilling the highly lipophilic dye onto the slice before patching the cell of interest. Dye bound to membrane outside the cell of interest would increase the background fluorescence $(F)$, thus degrading recording sensitivity. A whole-cell somatic recording was obtained from the selected neuron at room temperature $\left(22^{\circ} \mathrm{C}\right)$ under IR-DIC optics, and the dye was allowed to diffuse into the cell for 15-30 min. After filling, the patch electrode was removed from the neuron, forming an outside-out patch, and the cell was incubated at $35^{\circ} \mathrm{C}$ for at least $1 \mathrm{~h}$, allowing the dye to diffuse from the soma into distal processes. This dye has a slower diffusion rate compared with other dyes of similar size/weight due to its highly lipophilic nature. The filled neuron was then repatched near physiological temperature $\left(35^{\circ} \mathrm{C}\right)$ with a voltage-sensitive dye free patch electrode for simultaneous optical and electrophysiological recording. 
A

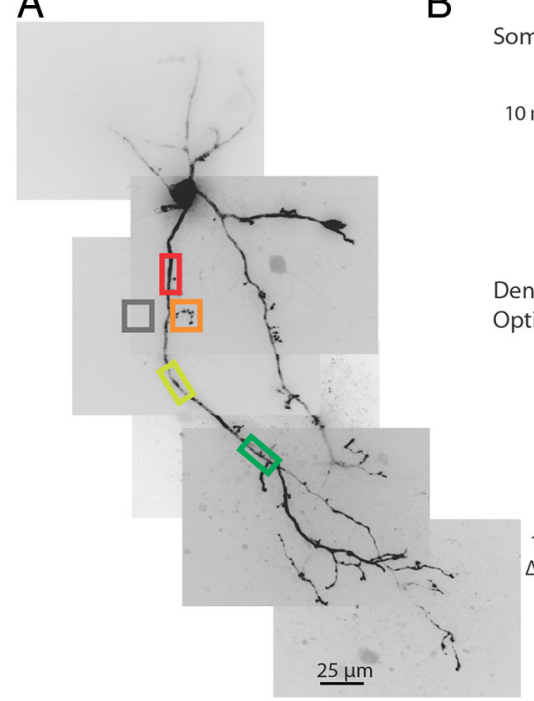

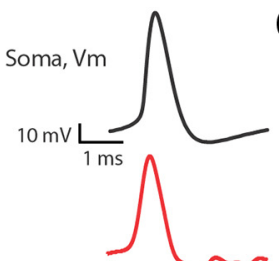

C

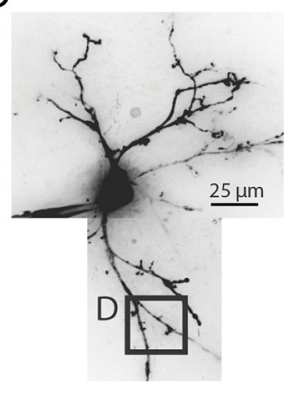

$\mathrm{D}$

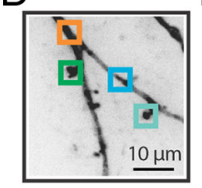

$\mathrm{F}$

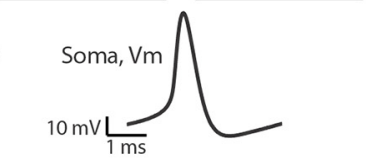

$\mathrm{E}$

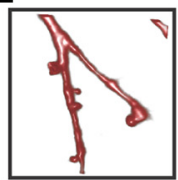

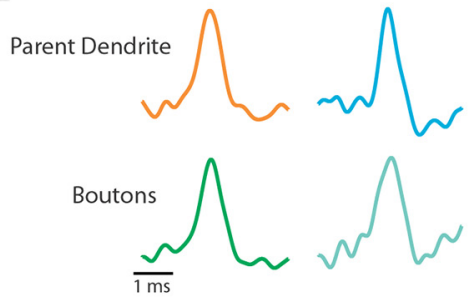

Figure 2. Action potentials propagate into the dendritic arbor and into dendritic boutons. $A$, Confocal $z$-projection of a voltage-sensitive dye-filled interneuron. Colored boxes are regions of interest for optical recordings in $\boldsymbol{B}$. B. Electrical and optical signals (average of four trials) of the first spike in a train elicited by a step depolarization at the soma. Optical traces were recorded at 10 kHz. Colored traces correspond to colored boxed regions in $A$. Note: gray trace demonstrates a lack of substantial light scatter, confirming that optical signals recorded are due to the dendritic region being imaged. $\boldsymbol{C}$, Confocal $z$-projection of a voltage-sensitive dye-filled interneuron. The dendritic region indicated by the black box (expanded in $\boldsymbol{D}$ and $\boldsymbol{E}$ ) was imaged with a resolution of $1 \mu \mathrm{m}$ per pixel at a speed of $10 \mathrm{kHz}$. D, Magnified confocal z-projection of dendritic region imaged. Colored boxes refer to regions of interest for optical recording. $\boldsymbol{E}$, Volume rendering of $z$-stack images of dendritic image shown in $\boldsymbol{D}$. $\boldsymbol{F}$, Electrical and optical signals (average of four trials) corresponding to the first action potential in a train elicited by a somatic step depolarization. Black trace is the electrical recording at the soma. Colored traces correspond to colored boxed regions of interest in $\boldsymbol{D}$. Optical traces are normalized to peaks.

Voltage-sensitive dye-filled neurons were illuminated with a $450 \mathrm{~mW}$ frequency-doubled, diode-pumped, Nd:YVO4 low-noise laser emitting at $532 \mathrm{~nm}$ (MLL532, Changchun New Industries Optoelectronics Technology). The laser beam was directed to a light guide coupled to the microscope via a single-port epifluorescence condenser (TILL Photonics) designed to overfill the back aperture of the objective. Backfilling the aperture allowed near uniform illumination of the object plane. Somatic illumination was limited by the microscope field-stop to minimize damage to the recorded neuron. Fluorescence from the stained cell was collected through the objective $(60 \times$ water-immersion, 1.0 numerical aperture, Nikon), long-pass filtered (RG610 HP, Schott), and projected onto a $80 \times 80$ pixel high-speed CCD camera with a $10 \mathrm{kHz}$ maximum frame rate (NeuroCCD-SMQ, RedShirtImaging) mounted at the front camera port of the trinocular tube. At the magnifications that we used, each pixel of the camera corresponded to a square region of 4,1 , or 0.4 $\mu \mathrm{m}$ per side, depending on the use of either no coupler (resulting in 0.4 $\mu \mathrm{m}$ per side), or installation of either a $0.3 \times$ or $0.1 \times$ coupler (serial 25-70-12 and RL091301-1, Optem). Reduced pixel sizes were ideal for identifying and optically recording fluorescence changes in dendritic boutons. Changes in voltage-sensitive dye fluorescence were recorded in response to action potentials initiated by intrasomatic current injections (50 or $5 \mathrm{~ms}$ duration) or local synaptic stimulation (theta glass bipolar, $200 \mu \mathrm{s}, 100-500 \mu \mathrm{A})$. Our first experiments, performed to determine voltage deflections in dendrites in response to somatically elicited action potentials, were optically recorded at a frame rate of $2 \mathrm{kHz}$ allowing the imaging of an $\sim 320 \times 320 \mu \mathrm{m}$ region of the LGNd simultaneously. At this frame rate, one to three trials could be averaged to achieve a signalto-noise $(\mathrm{S} / \mathrm{N})$ ratio of at least 6 . For assessment of action potential kinetics, we collected CCD images at $10 \mathrm{kHz}$, limiting the recording area to $320 \times 48 \mu \mathrm{m}$. At $10 \mathrm{kHz}, 1-10$ trials could be averaged to yield $\mathrm{S} / \mathrm{N}$ ratios of at least 4 . Action potential propagation into dendritic boutons typically required averages of $2-10$ trials to obtain suitable $\mathrm{S} / \mathrm{N}$ due to the decreased area of light collection. Optical recordings were also achieved in the presence of specific channel blockers to determine the participation of certain currents in dendritic action potential propagation.

To assess voltage-gated sodium channels, we bath applied TTX $(1 \mu \mathrm{m}$, Tocris Cookson) and recorded voltage-sensitive dye fluorescence changes in voltage-clamp in response to the application of action potential-like waveforms that were recorded in the same neurons before
TTX application. For these experiments, somatic fluorescence changes were monitored to ensure that injected waveforms caused somatic voltage changes similar to those seen during control (pre-TTX) conditions. It was sometimes necessary to multiply the injected waveform by a gain factor (1.5-4) to achieve fluorescence amplitude changes at the soma that were within $15 \%$ of control, presumably due to imperfect compensation of series access resistance, filtering by pipette capacitance, or space-clamp issues. Potassium channel experiments used bath application of TEA ( $1 \mathrm{~mm}$, Sigma-Aldrich) to block $\mathrm{K}_{\mathrm{v}} 3$ family channels, iberiotoxin (IBTX; $100 \mathrm{~nm}$, Tocris Cookson) to block calcium-activated potassium channels (BK channels), and $\alpha$-dendrotoxin ( $\alpha$-DTX; $100 \mathrm{nm,}$ Alomone Labs) to block low-threshold-activated $\mathrm{K}_{\mathrm{v}} 1$ family channels. During toxin experiments, a period of 5-10 min was used to collect one to five control conditions in the dendrite in response to somatically elicited action potentials before addition of the drug. After 5-10 min with the drug in the bath, the same dendritic location was imaged for 5-10 trials over $\sim 20 \mathrm{~min}$. Drugs were washed out for at least 20-30 min before 2-10 trials were obtained from the same dendritic region.

For local synaptic stimulation, a voltage-sensitive dye-filled dendrite, the dendrite of interest, was imaged on the CCD camera and a theta-glass stimulation electrode was positioned within $20-50 \mu \mathrm{m}$ of the dendrite and 50-100 $\mu \mathrm{m}$ away from the cell soma. Voltage-sensitive dye fluorescence changes were imaged in the dendrite of interest in response to a 50 ms somatic current injection that elicited one or more action potentials. The first action potential in this "control" condition served as a baseline assessment of fluorescence kinetics and propagation in response to a somatic action potential. We compared control condition kinetics and propagation to synaptically activated action potential kinetics and propagation. Trials lasted 20-100 ms, depending on the experimental conditions, and the voltage-sensitive dye was illuminated only during this period. We could obtain between 15 and 35 trials before changes in the electrophysiological properties of the recorded neuron (action potential amplitude and duration, resting membrane potential, resting input resistance) were evident ( $>10 \%$ of baseline values), in which case the experiment was terminated. After experimentation, confocal $z$-stacks were obtained of the voltage-sensitive dye-filled interneuron and its full dendritic arbor.

Computer simulations. Computer simulations were performed in a simplified three-compartment model (compartments contained seg- 
mentations of 1, 5, and 50 for the soma, axon and dendrite, respectively) of an LGNd interneuron using NEURON (Carnevale and Hines, 2006). The model cell consisted of a $15-\mu \mathrm{m}$-long cell body (diameter of $10 \mu \mathrm{m}$ ) to which a single dendrite with a length of $450 \mu \mathrm{m}$ and a linear diameter taper from 3.5 to $1.5 \mu \mathrm{m}$ was attached. A $50-\mu \mathrm{m}$-long axon with a diameter of $1 \mu \mathrm{m}$ was attached to the opposite side of the soma from the dendrite. The axial and membrane resistivity were set to $100 \Omega$-cm and $20 \mathrm{k} \Omega-\mathrm{cm}^{2}$, respectively. Other passive properties of the cell were as follows: $E_{\text {Leak }}=-65 \mathrm{mV}, E_{\mathrm{Na}}=60 \mathrm{mV}, E_{\mathrm{K}}=-90 \mathrm{mV}$, and membrane capacitance was set to $1 \mu \mathrm{F} / \mathrm{cm}^{2}$ for the soma and axon, and $2 \mu \mathrm{F} / \mathrm{cm}^{2}$ for the dendrite. Hodgkin and Huxley-like voltage-gated sodium channels were inserted in the axon $\left(g_{\mathrm{Na}}=8000 \mathrm{pS} / \mu \mathrm{m}^{2}\right)$ and soma $\left(g_{\mathrm{Na}}=200\right.$ $\mathrm{pS} / \mu \mathrm{m}^{2}$ ). A high-threshold-activated, fast-deactivating potassium channel was inserted into the axon and soma $\left(g_{\text {KHT }}=500 \mathrm{pS} / \mu \mathrm{m}^{2}\right)$. Parameters of voltage-gated channels were based on previously published experimental and modeling studies (McCormick and Huguenard, 1992; Mainen et al., 1995; Rothman and Manis, 2003; Yu et al., 2008). Synaptic inputs were simulated by an $\alpha$ function, $g=g_{\max } \times(T / \tau) \times e^{-(T-\tau) / \tau}$, where the time constant $\tau$ varied between 2 and $10 \mathrm{~ms}$ and $g_{\max }$ was varied between 0.001 and $0.1 \mathrm{nS}$.

Dendritic voltage-gated sodium channels and potassium channels were varied to assess the contribution of these channels to action potential propagation along the dendrite while the somatic and axonal conductances and passive properties of the model were held constant. In the $100-0 \%$ dendritic gradient, sodium and potassium conductances decayed linearly from $100 \%$ of the somatic value $\left(g_{\mathrm{Na}}=200 \mathrm{pS} / \mu \mathrm{m}^{2}, g_{\mathrm{KHT}}=\right.$ $\left.500 \mathrm{pS} / \mu \mathrm{m}^{2}\right)$ at the proximal dendrite to 0 conductance at the distal tip. Under the $50-25 \%$ dendritic condition, sodium and potassium conductances decreased linearly from $50 \%$ of the somatic conductance $\left(g_{\mathrm{Na}}=\right.$ $\left.100 \mathrm{pS} / \mu \mathrm{m}^{2}, g_{\mathrm{KHT}}=250 \mathrm{pS} / \mu \mathrm{m}^{2}\right)$ to $25 \%$ of the somatic conductance $\left(g_{\mathrm{Na}}=50 \mathrm{pS} / \mu \mathrm{m}^{2}, g_{\mathrm{KHT}}=125 \mathrm{pS} / \mu \mathrm{m}^{2}\right)$. In the passive condition, potassium conductances followed the linear decay described by the $50-25 \%$ condition, and no sodium conductance was included in the dendrite. Full-width at half-maximum amplitude, $10-90 \%$ rise time, $90-10 \%$ fall time, and amplitude of the action potential were calculated at each position along the dendrite. All simulations were performed at a temperature of $35^{\circ} \mathrm{C}$.

Data analysis. The $\mathrm{S} / \mathrm{N}$ of imaged voltage deflections varied from cell to cell depending in part on the concentration of dye and proximity of the dendrites to the surface of the slice. Thus, to achieve suitable $\mathrm{S} / \mathrm{N}$, we averaged fluorescence changes from groups of neighboring pixels (4$25)$. Although we typically could obtain a suitable $\mathrm{S} / \mathrm{N}$ in single-trial recordings, in some cases we averaged a small number (2-10) of trials. To avoid smearing in the trial-to-trial average because of temporal jitter, for each trial we shifted the signal in each pixel by the time needed to align the peak of the electrically recorded somatic action potential. A low-pass binomial filter (one to three passes) was applied to reduce highfrequency noise. Within-trial bleaching and low-frequency noise were removed by subtracting an exponential or polynomial function fit to the smoothed fluorescence signal. The waveforms of fluorescence action potential signals were cubic spline interpolated to $100 \mathrm{kHz}$ to precisely estimate certain kinetics of the waveform (e.g., width, 10-90\% rise time, $90-10 \%$ fall time). The width of the spike-associated fluorescence change was measured at the half-maximum amplitude. The $10-90 \%$ rise time of the fluorescence change was determined by calculating the difference between the time of 10 and $90 \%$ of the maximum amplitude of the fluorescence change from the preceding baseline fluorescence. The ratio of the change in fluorescence to the fluorescence level itself $(\Delta F / F)$ from different parts of the neuron varies due to factors other than voltage (e.g., density of dye, partitioning of dye in inner and outer membranes, depth of process in tissue), precluding any straightforward conversion of $\Delta F / F$ into voltage (Salzberg, 1983). The dye does, however, linearly follow voltage changes in the physiological range with microsecond precision (Salzberg et al., 1993), making a comparison of the kinetics of fluorescence changes in the dendrite a reliable measure. For characterization of changes in kinetics of fluorescence signals with distance from the soma, identical numbers of pixels were taken at different distances along the dendrite of a single cell. Additionally, waveforms from single cells received the same amount of low-pass filtering to accurately com-
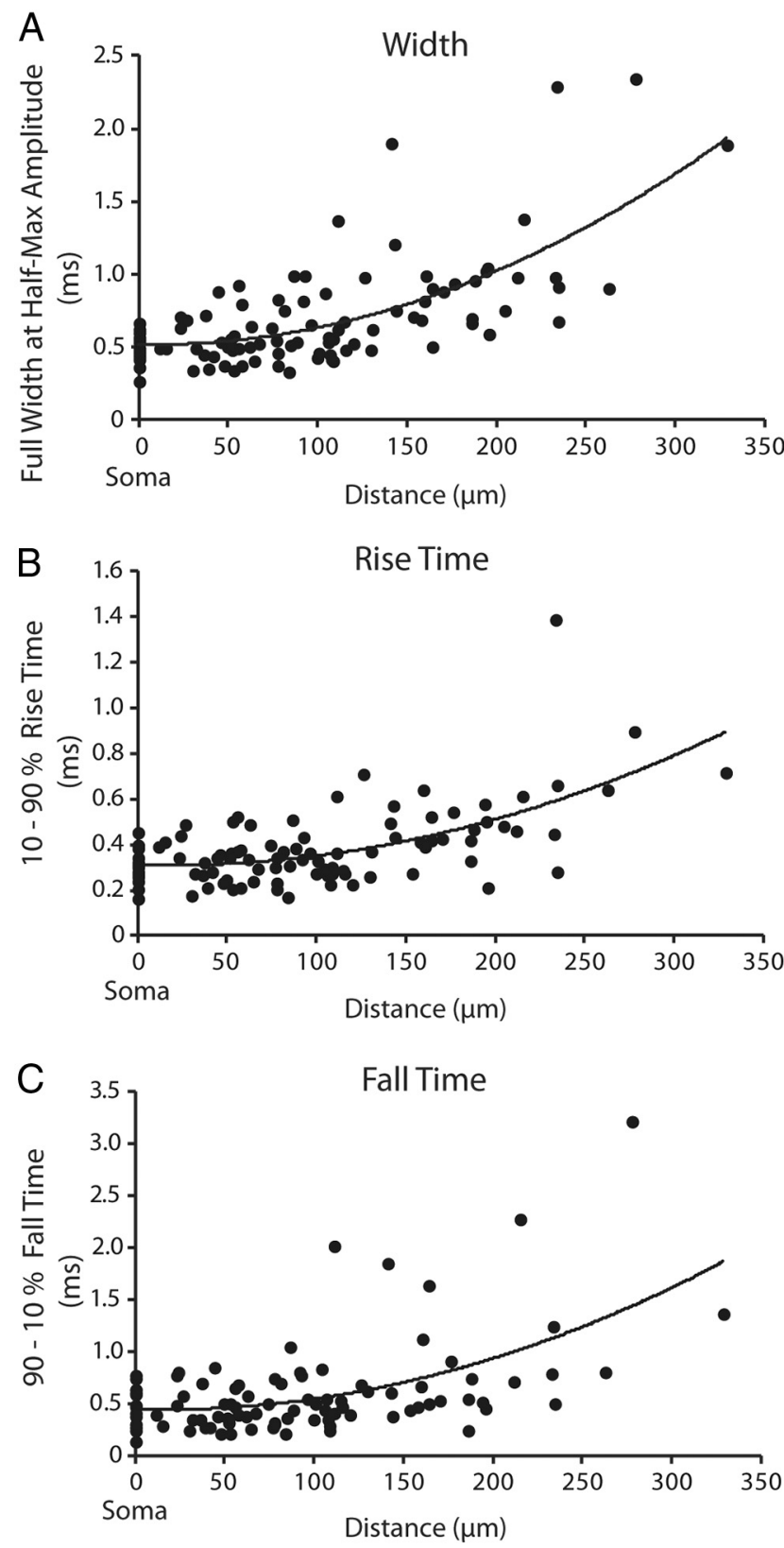

Figure 3. Action potentials become slower and broader as they propagate to the distal dendrite. $\boldsymbol{A}-\boldsymbol{C}$, Action potential full-width at half-height $\left(n=30 ; R^{2}=0.47\right)(\boldsymbol{A})$, action potential $10-90 \%$ rise time $\left(n=30 ; R^{2}=0.37\right)(B)$, action potential $90-10 \%$ fall time $(n=$ $\left.26 ; R^{2}=0.3\right)(C)$ plotted as a function of distance along the dendrite from the soma. Data were fit with a second-order polynomial. The somatic values (point 0 ) were recorded optically.

pare changes in waveform kinetics within a cell. The reported distance along the dendrite was determined with the program ImageJ (nih.gov) as the path length from the center of the soma to the center of the group of pixels averaged. The effects of blockers, or changes in stimulation protocol, were assessed by examining the changes in action potential waveform from the same pixels before, after, and following washout of each manipulation.

To determine propagation speed and direction, we compared the time of the half-maximum amplitude fluorescence change in the dendrite to that recorded optically at the edge of the soma. This method was superior to using either the foot or the peak of the action potentials, since both of these are characterized by a slowly changing membrane potential, allowing for substantial temporal jitter to be introduced by small variations in the accuracy of amplitude measurement. For experiments in which EP- 


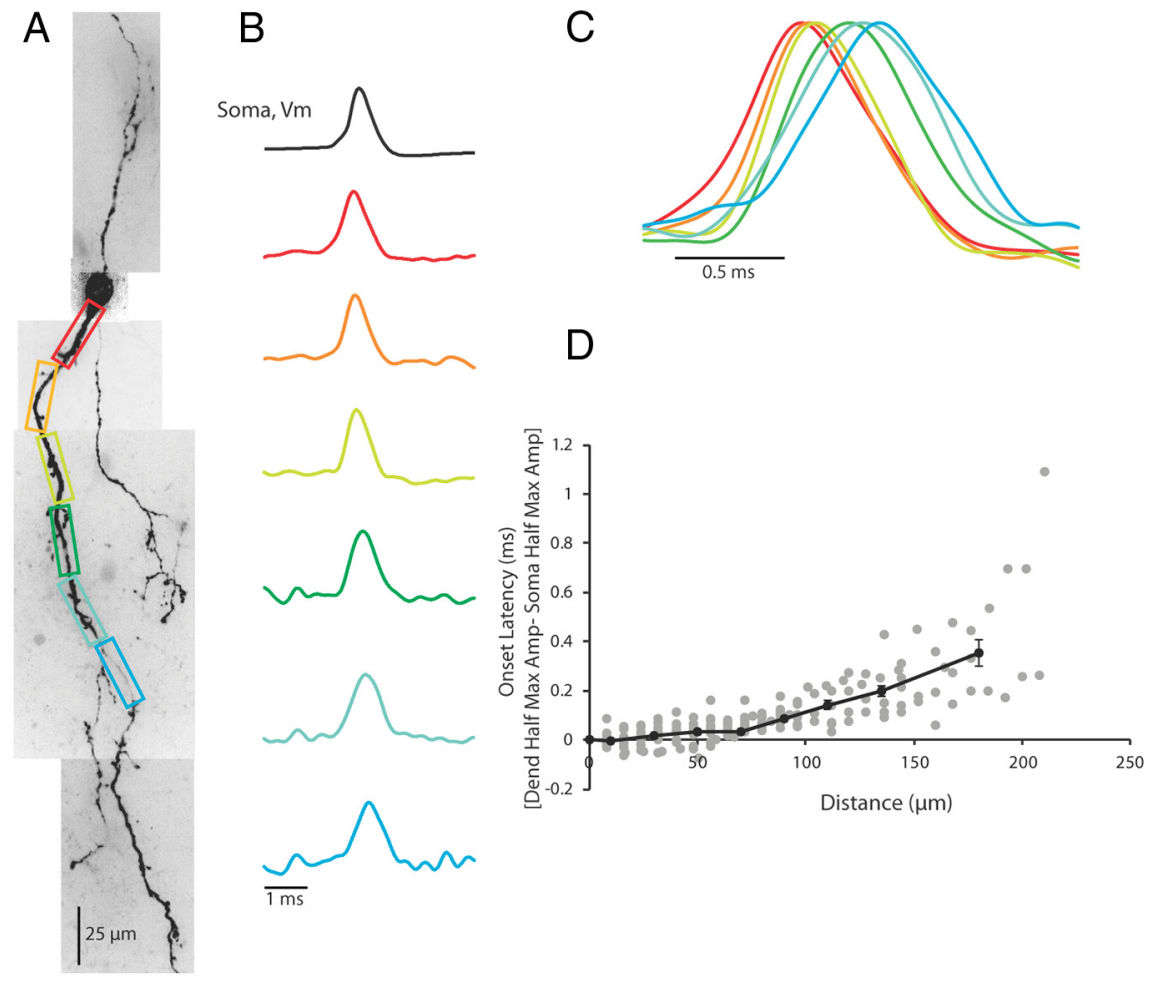

Figure 4. Action potentials occur first in the soma/proximal dendrite in response to a somatic step depolarization. $\boldsymbol{A}$, Confocal z-projection of a voltage-sensitive dye-filled interneuron. Colored boxes correspond to dendritic regions of interest. $\boldsymbol{B}$, Electrical and optical signals corresponding to the first action potential in a train. Electrical and optical signals are an average of three trials. Black trace is the somatic electrode recording. Colored traces are optical signals $(\Delta F / F)$ recorded at $10 \mathrm{kHz}$ along the dendrite. Colored traces refer to colored regions of interest in $A$. Optical and electrical traces are normalized to peaks. $\boldsymbol{C}$, Overlay of optical traces in $\boldsymbol{B}$ illustrating the timing of action potential occurrence in the dendrite. $\boldsymbol{D}$, Scatter plot of the onset latency of the action potential in the dendrite as a function of distance (gray dots). Onset latency was defined as the difference between the time of half-maximum amplitude of the action potential at the dendrite and the soma. Black line shows average onset latencies for bins of $20 \mu \mathrm{m}$ from 0 to $120 \mu \mathrm{m}$ along the dendrite. From 120 to $150 \mu \mathrm{m}$, data averaged in $30 \mu \mathrm{m}$ size bins. From 150 to $210 \mu \mathrm{m}$, data averaged in $60 \mu \mathrm{m}$ size bins. Error bars indicate \pm SEM. $N=14$ cells in $\boldsymbol{D}$. All data in plots are optical.

SPs were elicited by synaptic inputs, we used the electrical recording in the soma owing to the low $\mathrm{S} / \mathrm{N}$ ratio of somatic voltage-sensitive dye signal (which results from the presence of high background of dye bound to intrasomatic organelle membranes). To determine the location of EPSP initiation, we compared the time of the half-height of the EPSP in the somatic recording to the half-height of the fluorescence change in the dendrite. We confirmed this to be a valid method of analysis by comparing the timing of the half-height of action potentials at the soma between the electrical and optical recordings, which were not statistically different $(n=13, p>0.05)$.

\section{Results}

Action potentials propagate throughout the dendritic arbor and into putative dendritic boutons

To assess the propagation of action potentials into the thalamic interneuron dendritic arbor, we first used a $2 \mathrm{kHz}$ frame rate to image an $\sim 320 \times 320 \mu \mathrm{m}$ portion of the LGNd. This allowed us to image an entire section of voltage-sensitive dye-filled dendritic arbor on one side of the interneuron soma. Our imaging location could easily be moved between trials to determine the ability of a stimulus to cause voltage changes in the entire dendritic structure. At a $2 \mathrm{kHz}$ frame rate, we determined that action potentials elicited by somatic current injection caused action potentialshaped voltage deflections in the full dendritic arbor, including across branch points and into distal dendritic tips, even on single trials (Fig. $1 A, B ; n=5$ cells).
Increasing the sampling rate to $10 \mathrm{kHz}$ allowed us to assess more accurately the kinetics of the fluorescence changes in dendrites in response to intrasomatically elicited action potentials. Recording at the increased temporal resolution restricted our region of interest to an $\sim 320 \times 48$ $\mu \mathrm{m}$ section in which we could typically image one dendrite and its branches. Fluorescence changes representing action potentials occurred throughout the length of the sampled dendrite, invading all portions of each branch on every trial without failure (Fig. $2 ; n=30$ ).

The dendrites of thalamic interneurons release GABAergic vesicles from knob-like structures connected to the parent dendrite through fine, filiform appendages (Famiglietti, 1970; Famiglietti and Peters, 1972; Rafols and Valverde, 1973; Montero, 1986). We used high spatial $(1 \times 1$ or $0.4 \times 0.4 \mu \mathrm{m}$ per pixel $)$ and temporal $(10 \mathrm{kHz})$ resolution imaging to assess the ability of action potentials to invade these small dendritic boutons. Using an optical coupler, an $\sim 80 \times 12$ or $32 \times 5$ $\mu \mathrm{m}$ segment of dendrite containing putative dendritic boutons was imaged at a distance of $20-120 \mu \mathrm{m}$ from the soma. In response to a somatic current injection that elicited one or more action potentials, spike-shaped fluorescence changes were seen in both parent dendrites and putative dendritic terminals (Fig. 2C-F; $n=8$ cells, $n=12$ boutons). In four cells, multiple boutons on different dendrites arising from the soma were imaged. We found that action potentials invaded all dendrites and dendritic appendages regardless of which parent dendrite was imaged. Action potentials were also seen to propagate into dendritic appendages that occurred after dendritic branch points. Imaging regions of similar size to that of the dendritic appendages, except in a region not over any observed dendritic branch, resulted in no significant signal, indicating that the responses we observed were not due to light scatter (Fig. $2 A, B$ ). These results suggest that somatic action potentials reliably invade all dendritic branches and appendages.

The kinetics of the action potential as it propagated along the dendrite varied systematically with distance. The full-width at half-height, $10-90 \%$ rise time, and $90-10 \%$ fall time of the fluorescence signals increased with distance from the soma (Fig. $3 A-$ $C)$. The action potential became both slower and broader as it traveled into the distal regions of the dendrite. However, this was not true for local propagation of action potentials into the dendritic boutons. Comparison of full-width at half-height of the action potential between the parent dendrite and the adjacent dendritic bouton revealed no significant change in width $(p>$ $0.05)$. These results are similar to those reported for pyramidal cell dendritic spines (Holthoff et al., 2010).

With a $10 \mathrm{kHz}$ sampling rate, we could also examine the propagation of the action potential in the dendrite. We compared soma to dendrite latencies, defined as the difference between the time of action potential half-height at the dendrite and the soma, 
in contiguous regions spanning from the edge of the soma to $\sim 200 \mu \mathrm{m}$ down the dendrite. In response to intrasomatic current injection, action potentials were invariably found to appear first at the soma or proximal dendrite and propagate toward the distal dendrite (Fig. 4; $n=14$ cells). In rodent LGNd, the axon of local interneurons often arises from the trunk of a primary dendrite within $20-50 \mu \mathrm{m}$ of the soma (Rafols and Valverde, 1973; Perreault et al., 2003, their Fig. 1; AcunaGoycolea et al., 2008, their Fig. 2). Although we could not always identify axons in our recorded neurons, this anatomical arrangement is consistent with the finding that in a majority of our neurons $(n=$ 10/14) the action potential appeared in the proximal dendrite before the soma or distal dendrite. In the first $100 \mu \mathrm{m}$ of the dendrite, action potentials traveled at mean \pm SEM speeds of $1.09 \pm 0.12 \mathrm{~m} / \mathrm{s}$ ( $n=12$ cells), which is similar to the propagation speed of mammalian unmyelinated axons (Andersen et al., 2000; Meeks and Mennerick, 2007; Kress et al., 2008; Schmidt-Hieber et al., 2008; Yu et al., 2008; Foust et al., 2010; Popovic et al., 2011; for review, see Debanne et al., 2011), and faster than that typically associated with dendritic action potential propagation (Stuart and Häusser, 1994; Häusser et al., 1995; Stuart et al., 1997; Williams and Stuart, 2000; Antic, 2003; Djurisic et al., 2004; Shu et al., 2007, Nevian et al., 2007; Zhou et al., 2008; Ledergerber and Larkum, 2010). Interestingly, previous investigations of dendritic action potential propagation in fast-spiking GABAergic neurons of the hippocampus have also revealed rapid velocities (Martina et al., 2000 and $\mathrm{Hu}$ et al., 2010). The scatter plot of latency for contiguous 8 or $16 \mu \mathrm{m}$ sections of soma and dendrite clearly showed an increase in the time of spike latency with increasing distance from the soma (Fig. $4 D$, gray dots, $n=14$ ). Averaging the soma-to-dendrite latency for bins of $20 \mu \mathrm{m}$ for the first $0-120 \mu \mathrm{m}$ of the dendrite and then using bin sizes of 30 and $60 \mu \mathrm{m}$ for $120-150$ and $150-210 \mu \mathrm{m}$ distances, respectively, revealed an increasing delay in action potential latency (Fig. $4 D$, black line). Thus, it appears that in response to an intrasomatic current injection, action potentials initiate in the proximal somatodendritic (presumably axonal) region of the interneuron and propagate out into the distal dendrite. Although action potential propagation speed decreased with distance from the soma, it was rapid enough to result in the generation of an action potential at $\sim 200 \mu \mathrm{m}$ from the soma at a latency of $<0.4 \mathrm{~ms}$ (Fig. $4 D$ ). Since action potentials last $\sim 1 \mathrm{~ms}$, this rapid propagation speed ensures that the entire soma-dendrite axis of the local interneuron experiences the action potential nearly simultaneously.

\section{Multiple action potentials propagate reliably into interneuron dendrites}

Response properties of feline thalamic interneurons to visual stimuli in vivo are often similar to those of X-type thalamocortical cells (Sherman and Friedlander, 1988). In the mouse, the LGNd is composed primarily of thalamocortical cells that exhibit X-type characteristics (e.g., sustained activation and linear summation of visual stimuli) (Grubb and Thompson, 2003). X-type thalamocortical cells in the mouse can respond to sinusoidal grating in a preferred phase with firing rates between 40 and $130 \mathrm{~Hz}$ (tonic and burst mode, respectively) [Grubb and Thompson, 2003 (their Fig. 2), 2005 (their Fig. 5)]. Here we examined the effects of action potential trains on shape and reliability during propagation into interneuron dendrites at frequencies within range of those observed in mouse relay cells (imaging rates of $2-10 \mathrm{kHz}$ ). Somatic step depolarizations $(50 \mathrm{~ms})$ were calibrated to elicit three to five action potentials, and changes in fluorescence were monitored in response to each spike (Fig. 5). In response to a current step of $80 \mathrm{pA}$, the cell in Figure 5 evoked four action potentials that were readily recorded optically in the dendritic branch in a single trial (Fig. 5C,D). In 14 of 14 cells tested, we were able to detect changes in voltagesensitive dye fluorescence in response to every action potential that occurred during the somatic step depolarization. Multiple action potentials could also be tracked across branch points. Trains of action potentials reliably propagated into the entire dendritic arbor.

Despite the reliable propagation of action potentials into the interneuron dendrite and across branch points, the amplitude of action potentials in a train decreased as measured both electrically at the soma and optically in the dendrite $(p<0.01$ soma and dendrite) (Fig. 5D). Closer examination revealed not only a decrease in the amplitude of the spike, but also an increase in the rise time at both regions ( $p<0.05$ soma, dendrite $10-90 \%$ rise times) (Fig. $6 E$, black bars: soma; gray bars: dendrite). There were 

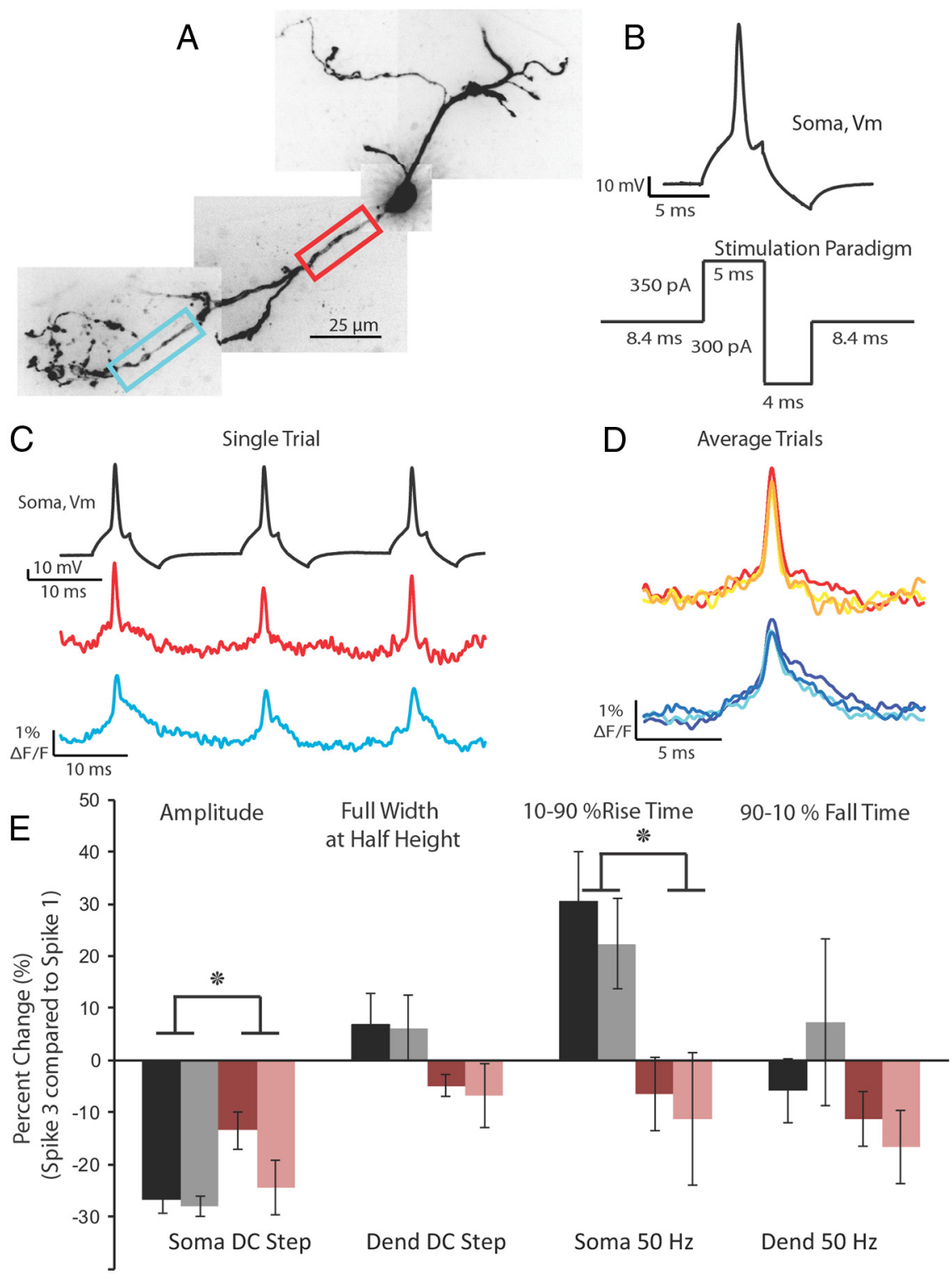

Figure 6. Action potential height decay during trains can be relieved using a $50 \mathrm{~Hz}$ depolarizing/hyperpolarizing stimulation protocol. A, Confocal z-projection of a voltage-sensitive dye-filled interneuron. Colored boxes refer to the dendritic regions of interest during imaging. $\boldsymbol{B}$, Example of the $50 \mathrm{~Hz}$ stimulation protocol used to relieve spike height decay. $\boldsymbol{C}$, Single-trial example of the multiple action potentials propagating into the dendrite in response to the stimulation protocol in $\boldsymbol{B}$. Optical traces were taken from the color boxed regions of interest in $\boldsymbol{A}$. Note the lack of extreme action potential height decay. $\boldsymbol{D}$, Overlay of three action potentials in a $50 \mathrm{~Hz}$ train; average of two trials. E, Summary of action potential kinetics (amplitude, full-width at half-height; $10-90 \%$ rise time; $90-10 \%$ fall time) expressed as the percentage change between the first and third spike in a train. Black and gray bars refer to changes in action potential waveform at the soma and dendrite, respectively, in response to a $50 \mathrm{~ms}$ somatic current injection. Rose and pink bars refer to the changes in action potential waveform at the soma and dendrite, respectively, in response to the $50 \mathrm{~Hz}$ stimulation protocol (as shown in $\boldsymbol{B}$ ).

no significant changes in the full-width at half-height or the $90-$ $10 \%$ fall time of the action potential $(p>0.2)$.

An increased time for the rising phase of the action potential could be due to a decrease in the availability of voltage-gated sodium channels, owing to depolarization-induced inactivation of sodium channels. To test this hypothesis, we devised a stimulation protocol consisting of a $5 \mathrm{~ms}$ somatic depolarization to elicit an action potential followed by a $4 \mathrm{~ms}$ hyperpolarization at a frequency of $50 \mathrm{~Hz}$ (Fig. 6B). When the cell was stimulated with a $5 \mathrm{~ms}$ depolarization that elicited action potentials at $50 \mathrm{~Hz}$ without the hyperpolarizing step, we found a rapid reduction in the amplitude of the action potential recorded electrically at the soma (data not shown). This change in height may be attributable to a long-lasting afterdepolarization that occurred following the spike since subsequent action potentials were elicited during this period of depolarization. A strong (300-350 pA) hyperpolarizing pulse, however, could relieve the afterdepolarization and return the somatic membrane potential close to rest. In response to the $50 \mathrm{~Hz}$ depolarizing/ hyperpolarizing protocol, or to a steady $50 \mathrm{~ms}$ step depolarization, action potentials propagated throughout interneuron dendrites (Fig. 6C,D). The depolarizing/ hyperpolarizing protocol significantly reduced the amount of spike height decay between the first and third spike in a train when compared with the $50 \mathrm{~ms}$ step depolarization ( $p<0.01$, two-way ANOVA). However, there remained a significant decrease in spike height at the soma and dendrite ( $p<0.05$ soma and dendrite). Additionally, the $50 \mathrm{~Hz}$ protocol eliminated the increase in the rise time of the action potential compared with the $50 \mathrm{~ms}$ step depolarization $(p<0.01$, two-way ANOVA).

These results suggest that although multiple action potentials can reliably propagate throughout the dendritic arbor, recent dendritic activity can affect the availability of sodium channels and thus alter the amplitude and rising phase of subsequent action potentials.

\section{Action potentials rely on voltage-gated sodium channels and TEA-sensitive potassium channels for dendritic propagation}

Dendritic action potential propagation can be active or passive (for review, see Migliore and Shepherd, 2002). To test the dependence of dendritic action potential propagation on voltage-gated sodium channels in thalamic interneurons, we examined the effects of $\mathrm{Na}^{+}$channel block with TTX. Under control conditions, action potentials elicited by somatic current injection readily propagated throughout the dendritic arbor (Fig. 7). Following the abolition of endogenous action potentials with the bath application of TTX $(1 \mu \mathrm{M})$, we used a scaled version of the previously recorded action potential from control conditions as a voltage command to the soma. We adjusted the amplitude of the injected waveform such that the injected stimulus waveform caused a change in fluorescence change at the soma in TTX that was within $15 \%$ of that recorded under control conditions (Fig. $7 B$, red and gray). We found that in the presence of TTX the amplitude of the stimulus waveform decreased rapidly and significantly with distance along the dendrite, when compared with control conditions (Fig. $7 B-D ; p<0.01$ 
A

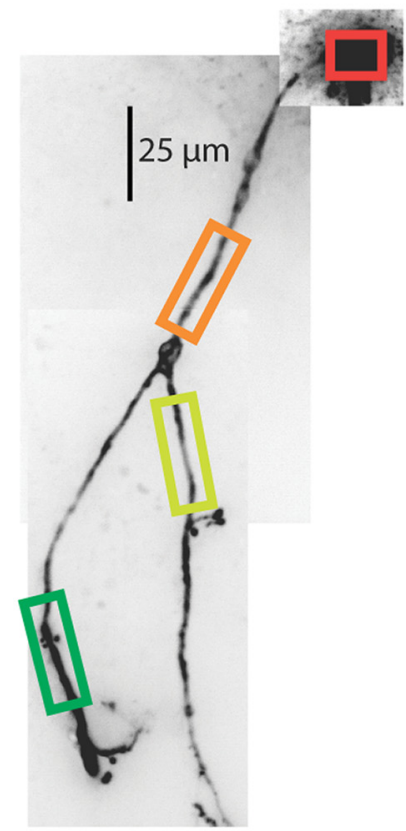

B

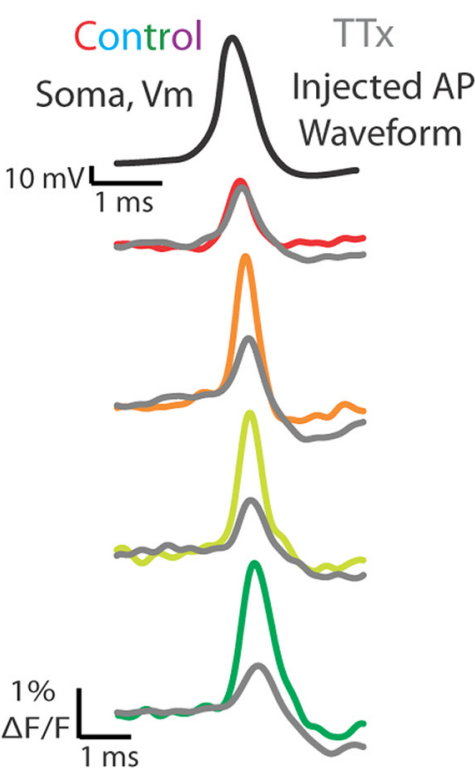

C
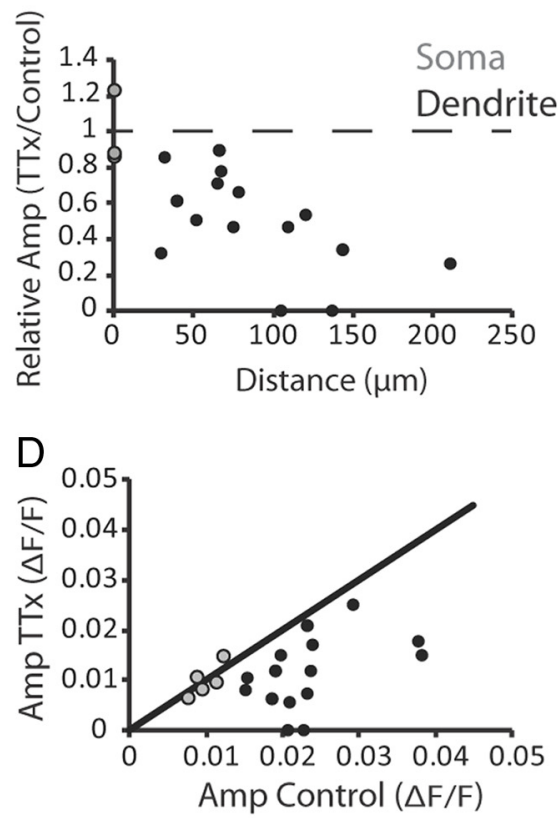

Figure 7. Action potentials rely on voltage-gated sodium channels to propagate into the dendrite. $A$, Confocal z-projection of a voltage-sensitive dye-filled interneuron. Colored boxes indicate dendritic regions of interest during imaging. $\boldsymbol{B}$, Electrical and optical signals corresponding to an action potential or an injected action potential waveform in control or $1 \mu \mathrm{m}$ TTX conditions. Black trace is the action potential recorded by the electrode at the soma during control. This action potential served as the injected waveform in the presence of TTX. Colored traces correspond to data obtained from somatic and dendritic regions of interest seen in $\boldsymbol{A}$ during control conditions (average of three trials). Gray traces are fluorescence changes in response to the injected action potential waveform (average of 5 trials). C, Relative amplitude of the fluorescence (TTX/Control) plotted against distance along the dendrite. Gray circles represent somatic change. Black circles represent dendritic changes. D, Plot of action potential amplitude $(\Delta F / F)$ during TTX and control conditions. Gray circles represent somatic $\Delta F / F$. Black circles represent dendritic $\Delta F / F$. Black line represents unity. Only optical signals were compared at the soma. $N=5$ cells.

at the dendrite; $p=0.8$ at the soma; $n=5$ cells). These results demonstrate that action potentials are actively propagated into interneuron dendrites through the activation of voltageactivated $\mathrm{Na}^{+}$channels.

Potassium currents are involved in controlling the propagation and repolarization of dendritic action potentials (Hoffman et al., 1997; Williams and Stuart, 2000; Christie and Westbrook, 2003; Johnston et al., 2003; Nevian et al., 2007). To determine the role of three classes of $\mathrm{K}^{+}$current in spike propagation and repolarization in interneuron dendrites, we bath applied the following: TEA ( $1 \mathrm{~mm})$, a blocker of high-threshold activated $\mathrm{K}_{\mathrm{v}} 3$ family channels $(n=4)$; IBTX (100 nM), a blocker of calciumactivated potassium BK channels $(n=4)$; and $\alpha$-DTX (100 nM), a blocker of low-threshold-activated $\mathrm{K}_{\mathrm{v}} 1$ family channels $(n=5)$ (Fig. 8). None of the drugs tested affected the ability of action potentials to propagate into distal regions of the dendrite. Of the drugs tested, only TEA had a significant effect on action potential width at half-height at the soma and dendrite (Fig. 8D). Application of TEA also reduced or abolished the fast-spike afterhyperpolarization in both the soma and dendrite (Fig. 8A). This pharmacological profile suggests that high-threshold-activated, fast-deactivating $\mathrm{K}_{\mathrm{v}} 3$ family $\mathrm{K}^{+}$channels may play a significant role in shaping the falling phase of the dendritic and somatic action potential waveform.

\section{Action potentials do not initiate in the interneuron dendrite} in response to local synaptic stimulation

In certain types of interneurons in the hippocampus and in mitral cells of the olfactory bulb, it has been suggested that $\mathrm{Na} / \mathrm{K}$ dependent action potentials can initiate in the dendrite (Martina et al., 2000, Djurisic et al., 2004), although in the vast majority of neurons action potentials typically initiate in the axon initial segment (Khaliq and Raman, 2006; Shu et al., 2007, Kole and Stewart, 2008; Kole et al., 2008; Yu et al., 2008; Foust et al., 2010; Hu et al., 2010; Palmer et al., 2010). The participation of voltage-gated sodium channels in the propagation of the action potential in the LGNd interneuron dendrite raises the possibility that action potentials could initiate in the dendrite proper. To assess this possibility, we examined dendritic voltage responses to somatic current injection and synaptic inputs elicited by a theta-glass stimulator (placed within $50 \mu \mathrm{m}$ of a voltage-sensitive dyelabeled dendrite at distances of $\sim 50-150 \mu \mathrm{m}$ away from the interneuron soma). Single current pulses (100-500 $\mu \mathrm{A}, 0.2 \mathrm{~ms}$ duration) were delivered to the neuropil through the theta-glass stimulator. The current needed to elicit a synaptically activated action potential was determined and the stimulus intensity subsequently reduced by $\sim 5 \%$ to cause just subthreshold EPSPs (Fig. $9 B, C ; n=5)$. Depending on the signal-to-noise ratio, single trials or averages of a few (less than five) trials were used to identify the location and onset latency of EPSPs in the imaged dendrites. Soma-to-dendrite latency was determined as the difference between the timing of action potential half-height at the dendritic region where the EPSP occurred first and the soma for both synaptically and intrasomatically elicited action potentials. For all cells tested, action potentials evoked by intrasomatic injection or synaptic stimulation appeared first at the soma and propagated to the dendritic region of interest (i.e., the dendritic location first to show an EPSP) (Fig. 9D; $n=5$ ). Reducing the stimulus intensity slightly (e.g., 5\%) to just below somatic spike threshold always abolished the occurrence of an action potential in the dendrite. We did not observe any dendritic $\mathrm{Na} / \mathrm{K}$ action potential-shaped voltage 

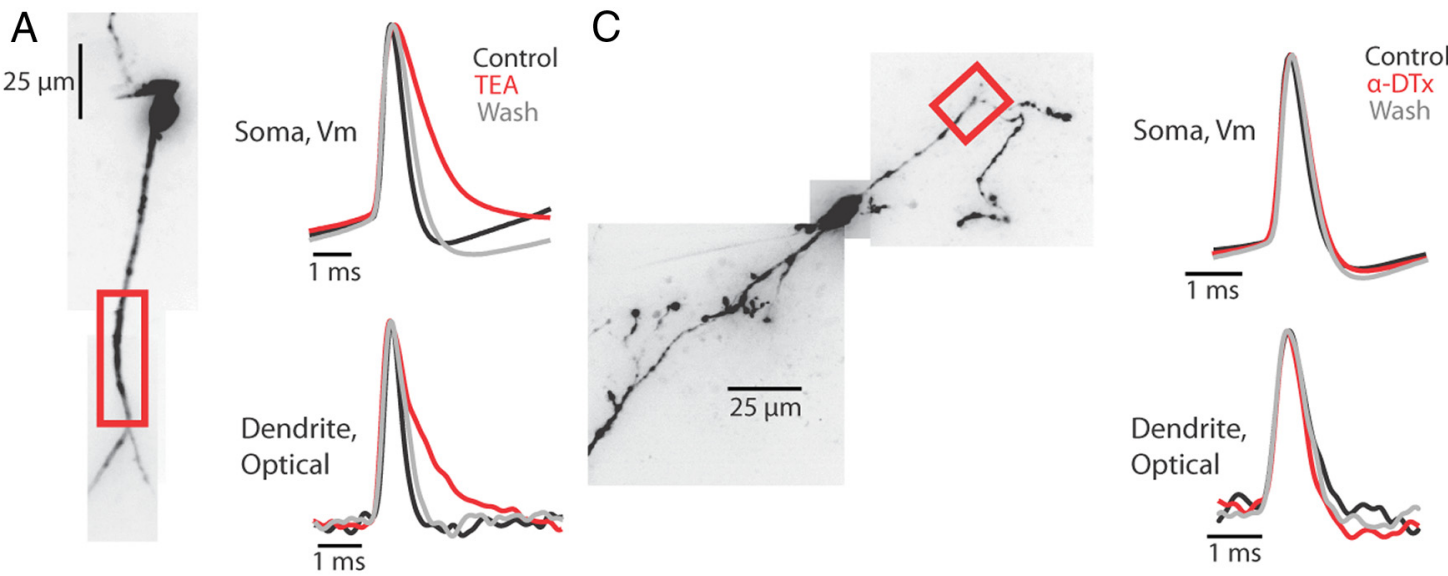

B

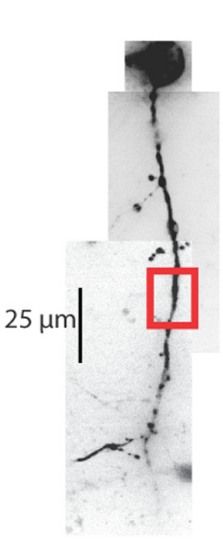

D

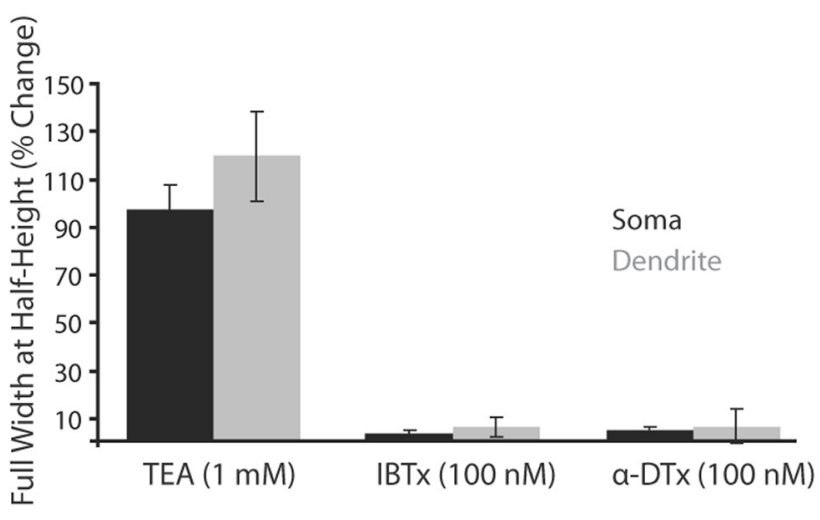

Figure 8. TEA-sensitive potassium channels control the repolarizing phase of the action potential. $\boldsymbol{A}$-C, Left, Confocal z-projection of a voltage-sensitive dye-filled interneuron. Colored box refers to the dendritic region of interest during imaging. Right, examples of action potential waveform recorded electrically at the soma or optically in the dendrite during control, drug, and wash conditions. Concentrations: TEA $1 \mathrm{~mm}$, IBTX $100 \mathrm{nM}, \alpha$-DTX $100 \mathrm{nM}$. D, Summary of drug effects on the action potential full-width at half-height expressed as a percentage of control (average \pm SEM). Black bars are somatic waveform changes recorded electrically (TEA: $n=6$; IBTX: $n=5 ; \alpha$-DTX: $n=6$ cells). Gray bars are dendritic waveform changes recorded optically (TEA: $n=4$; IBTX: $n=4 ; \alpha$-DTX $n=5$ cells).

response in the absence of somatic spiking, even for just subsomatic-threshold synaptic stimuli.

Interestingly, the soma-to-dendrite latency was greater for action potentials elicited by synaptic stimulation (compared with somatic current injection), suggesting that the speed with which the action potential propagated back into the dendrites was decreased (Fig. 9D; $p<0.05$ ). We hypothesize that this decreased conduction velocity may have resulted from $\mathrm{Na}^{+}$channel inactivation owing to the strong dendritic depolarization during the EPSP. Indeed, action potentials elicited by synaptic inputs were significantly smaller in the dendrite of interest than those elicited by current injection into the soma $(p<0.01)$, even though these action potentials were not significantly different in amplitude at the soma $(p>0.05)$.

\section{Computer simulation of interneuron dendrites}

Our experimental evidence shows that action potentials propagate actively into interneuron dendrites, but become both slower and broader as they do so. Furthermore, action potential propagation speed decreases with distance from the soma, and action potentials themselves fail to initiate in the distal dendrite. Here we explore possible distributions of sodium and potassium channel densities in the interneuron dendrite that might account for these results in a simplified threecompartment model (Fig. 10A).
Sodium and potassium maximal conductances were held constant in the axon and soma while dendritic maximal conductances were systematically altered. We examined three different hypothetical distributions of dendritic conductances (see Computer simulations in Materials and Methods). The first condition used a linear decay of sodium and potassium conductances from $100 \%$ of the somatic value at the proximal dendrite to 0 active conductances at the distal tip. The second condition used a linearly decaying distribution that started at $50 \%$ of the somatic conductances and decayed to $25 \%$ at the distal dendrite. The final condition, termed "passive," had identical dendritic potassium conductances to the $50-25 \%$ condition, but no sodium conductances were included in the dendrite. For all three models, action potentials were never initiated in the dendrite proper when stimulated by a dendritic current injection or by a synaptic input simulated by an $\alpha$ function (see Materials and Methods) located at 50 or $150 \mu \mathrm{m}$ from the cell soma (action potentials were initiated in the axonal compartment only; data not shown). Both the $50-25 \%$ and passive conditions were also able to mimic the spike height decay seen in a train of action potentials recorded electrically at the soma in response to a somatic step depolarization ( $50 \mathrm{~ms}, 200 \mathrm{pA}$ ). Comparing the results of the three models revealed that the $100-0 \%$ and $50-25 \% \mathrm{Na}^{+}$gradients yielded increases in spike latency (Fig. 10C) and decreases in spike rise time (Fig. 10E) that fit those observed in real neurons better than 
A
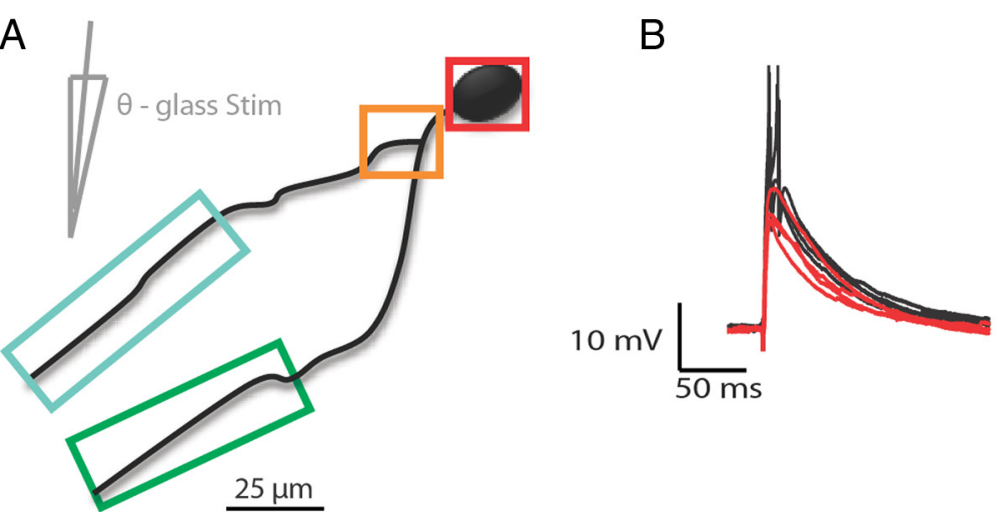

C Somatic Stim

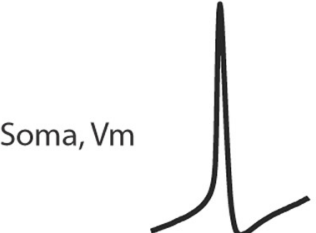

Subthreshold

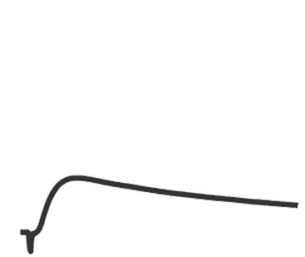

Soma, $\Delta F / F$
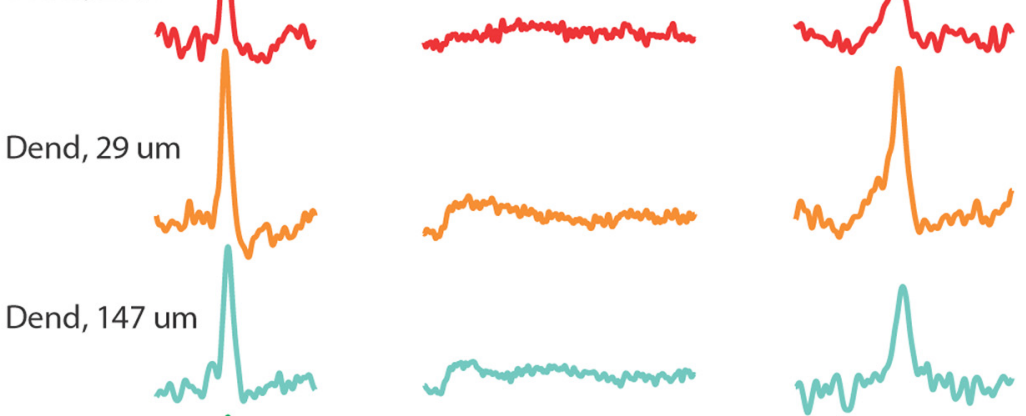

Dend, 125 um

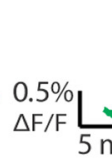

D

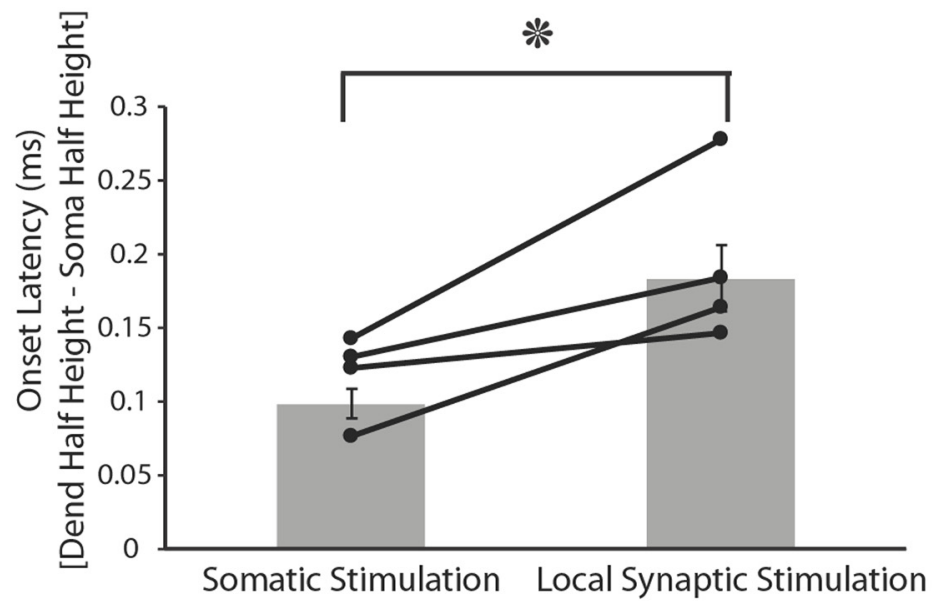

Figure 9. Action potentials elicited by either somatic current injection or local synaptic stimulation appeared first in or near the soma. $\boldsymbol{A}$, Illustration of a voltage-sensitive dye-filled cell and theta-glass stimulator. Colored boxes correspond to somatic and dendritic regions of interest during imaging. $\boldsymbol{B}$, Overlay of subthreshold (red) and suprathreshold (black) electrical signals recorded at the soma in response to local synaptic stimulation. Action potentials are truncated for clarity. $\boldsymbol{C}$, Electrical and optical signals corresponding to action potentials elicited by somatic current injection (average of 2 trials), local synaptic stimulation resulting in subthreshold events (average of 10 trials), or local synaptic stimulation that elicited action potentials (average of 3 trials). 0 wing to variations in performance of the dye, differences in $\Delta F / F$ between locations is not necessarily indicative of differences in actual voltage. $\boldsymbol{D}$, Onset latency of action potentials elicited by either somatic current injection or local synaptic stimulation. Onset latency the passive dendritic model. In addition, the $50-25 \% \mathrm{Na}^{+}$gradient model gave a better fit to the increase in fall time of the action potential (Fig. $10 \mathrm{~F}$ ), and increased spike width (Fig. 10D), with dendritic distance, than found with either the passive or $100-0 \% \mathrm{Na}^{+}$gradient models. An interesting result of this simulation was that increased sodium conductance in the dendrite increased the onset latency of the action potential, compared with the passive propagation of the spike (Fig. 10C, Onset Latency), presumably owing to the time required to actively generate an action potential at each dendritic compartment.

A drawback of VSD imaging is that an absolute voltage cannot be determined from the amplitude of the fluorescence signal. Creating a computer simulation that was constrained by our experimental data allowed us to predict the amplitudes of the voltage changes in the dendrites of LGNd interneurons. Action potential amplitudes, calculated from threshold, were found to decrease with distance from the soma for all conditions, although the reduction in amplitude was much less in the active than the passive condition (Fig. $10 G$, Amplitude). To assess how well the $50-25 \%$ conductance model fit with our dendritic experimental data, we treated the $50-25 \%$ and passive conditions as a replication of our TTX experiment. The relative amplitude change between the $50-25 \%$ and passive conditions were compared with those found experimentally between control and TTX conditions (Fig. $10 \mathrm{H}$, Relative Amplitude: black dots, experimental; rose dots, model data). We found that the relative change in amplitude determined by our model data was approximately similar, without the variation of biological results, to that found experimentally. These results further support a model in which interneuron dendrites actively propagate action potentials with a distance-dependent decay in density of sodium and potassium channels.

\section{Discussion}

Inhibitory local circuit neurons in the thalamus are among a number of cells in

is defined as the difference between the time of action potential half-height at the dendrite and soma. This difference was calculated for action potentials at the soma and the dendrite where EPSPs occurred first. Connected points correspond to a single cell in which action potentials were evoked somatically or synaptically ( $n=5$ cells). Gray bars are average onset latency \pm SEM. Note that propagation speed decreased for action potentials elicited by local synaptic stimulation $(p<0.05)$. 

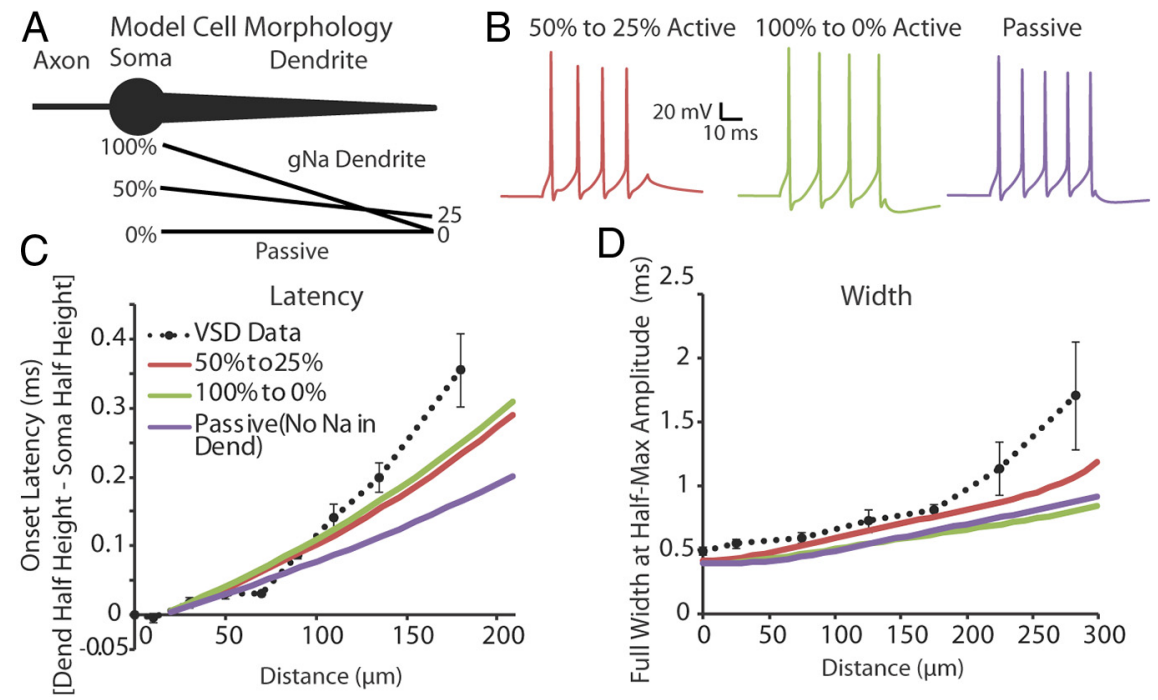

$\mathrm{D}$
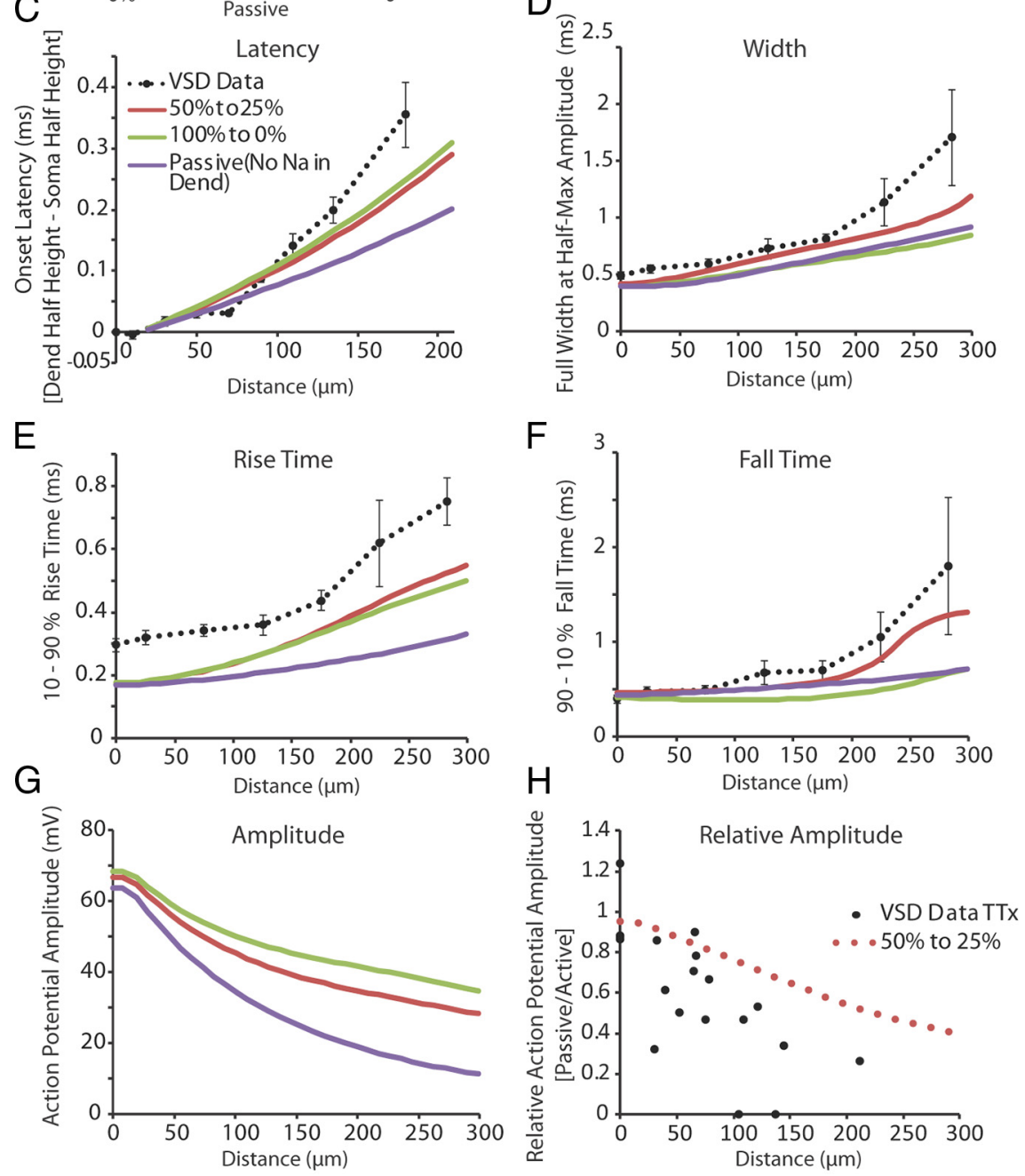

Figure 10. A Aradient of voltage-gated sodium and potassium channels along the dendrite can explain much of the broadening and slowing velocity of an action potential as it propagates away from the soma. $\boldsymbol{A}$, Illustration of the model cell morphology. The simplified three-component morphology included an axon, cell body, and a single tapering dendrite. Black lines below the dendrite correspond to gradients in the sodium conductance along the dendrite as a percentage of that found in the soma (see Materials and Methods, Computer simulation). The potassium conductance followed the same linear percentage gradient as the sodium distribution for each condition, except during Passive where it was set to $50-25 \%$ of the somatic potassium conductance. $B$, Example of spiking behavior recorded at the soma in response to a $50 \mathrm{~ms}, 200 \mathrm{pA}$ step depolarization at the model soma under each of the different dendritic conditions. $(-\boldsymbol{F}$, Onset latency, full-width at half-height, $10-90 \%$ rise time, and $90-10 \%$ fall time of the first action potential in a train (elicited by a somatic step depolarization; $50 \mathrm{~ms}, 200 \mathrm{pA}$ stimulation) recorded along the length of the dendrite. Dashed black lines correspond to experimental data collected using voltage-sensitive dyes. Experimental data were binned in 50 and $66 \mu \mathrm{m}$ (Width, Rise Time, Fall Time) or 20, 30, and $60 \mu \mathrm{m}$ (Soma to Dendrite Latency) segments (average \pm SEM). G, Predicted action potential amplitude as a function of distance along the dendrite. $\boldsymbol{H}$, In support of the model, the predicted ratio of action potential amplitude before and after TTX application versus distance along the dendrite is approximately correct.

the brain that can release synaptic vesicles from both their axons and dendrites (Famiglietti, 1970; Famiglietti and Peters, 1972; Rafols and Valverde, 1973; Montero, 1986; Scheetz and Dubin, 1994; Acuna-Goycolea et al., 2008) (for review, see Kennedy and Ehlers, 2011). Synaptic vesicle release from axonal boutons is typically triggered by a rapid and high increase in local $\left[\mathrm{Ca}^{2+}\right]_{i}$ initiated by an action potential. The mechanisms of release of synaptic vesicles from dendrites is also $\mathrm{Ca}^{2+}$ dependent (Isaacson and Strowbridge, 1998; Isaacson, 2001; Zelles et al., 2006; Acuna-Goycolea et al., 2008; Abraham et al., 2010; Errington et al., 2011), although it is unclear whether or not synaptic vesicle release from dendrites is as dependent upon action potentials as is axonal release, and whether or not individual dendritic branches may operate independently from the axon or other dendrites. This is particularly true for thalamic interneurons, which contain filiform appendages characterized by long (e.g., $10 \mu \mathrm{m})$, thin $(\sim 0.1 \mu \mathrm{m})$ dendritic stalks that separate the site of synaptic release (and reception of subthalamic or retinal presynaptic inputs) from the parent dendrite (Rafols and Valverde, 1973). Computational simulations of the electrotonic structure of thalamic interneurons have led to the hypothesis that the dendritic and axonal portions of these cells operate independently, assuming that dendrites are passive, with axosomatic action potentials causing release of GABA from axonal terminals only (Bloomfield and Sherman, 1989; Briska et al., 2003).

But, are thalamic interneuron dendrites passive? Can action potentials invade dendritic presynaptic boutons? Previous studies in thalamic interneurons suggest that somatic action potentials can propagate and cause $\mathrm{Ca}^{2+}$ transients in dendritic regions, and that this depends upon voltage-gated $\mathrm{Na}^{+}$channels (AcunaGoycolea et al., 2008). The small diameter of these dendrites, however, precluded the direct demonstration through electrical recording that action potentials actively propagate from the somatic regions into the regions of dendritic synaptic release. Here, using high-speed and high-resolution VSD imaging, we demonstrate that action potentials initiated in the somatic region propagate robustly and rapidly into all regions of the dendritic arbor, including the fine appendages associated with dendritic synaptic vesicle release. This propagation was supported by voltage-gated sodium channels and TEA-sensitive potassium channels. Furthermore, action potential conduction velocity was similar to that for unmyelinated mammalian axons (Andersen et al., 2000; Meeks and Mennerick, 2007; Kress et al., 2008; Schmidt-Hieber et al., 2008; Yu et al., 2008; Foust et al., 2010; Popovic et al., 2011; for review, see Debanne et al., 2011).

The ability to receive synaptic inputs, integrate them into voltage deviations at the soma/axon initial segment, and then rapidly propagate $\mathrm{Na}^{+}$-dependent action potentials at a rate typical for unmyelinated axons and release synaptic vesicles in an action 
potential-dependent manner indicates that these morphological processes possess functional properties between those traditionally associated with dendrites and axons. We propose the term "dendraxons" to emphasize this dual role. One important feature of these processes that is different from axonal conduction is the apparent decrease in amplitude and slowing of the kinetics of the action potential as it propagates through dendritic processes. Even so, we found that the entire dendritic arbor of local interneurons, including the fine appendages that release synaptic vesicles, will experience the action potential nearly simultaneously, within $\sim 0.5 \mathrm{~ms}$.

The broadening and slowing in kinetics of the action potential as it propagates into the dendrite is consistent with a decaying density of voltage-activated sodium and potassium conductances with distance from the soma. These lower densities of $\mathrm{Na}^{+}$channels may also explain why we never observed action potentials to initiate in dendritic branches, even with strong synaptic stimulation. Whenever action potential threshold was reached, spikes initiated first in the somatic or near-somatic region (presumably axonal), versus the distal dendritic region. However, evidence suggests that dendritic release of neurotransmitter can occur without $\mathrm{Na}^{+}$-dependent action potentials. Following the block of voltage-dependent $\mathrm{Na}^{+}$currents with TTX, the activation of glutamate metabotropic receptors results in a large increase in IPSP rate in thalamocortical neurons (Cox and Sherman, 2000; Govindaiah and Cox, 2004, 2006; Errington et al., 2011), a result consistent with interneuronal dendritic depolarization and release of synaptic vesicles. Similarly, the initiation of prolonged $\mathrm{Ca}^{2+}$-dependent action potentials in thalamic interneurons appears to result in the prolonged release of GABAergic vesicles from these dendrites, even in the absence of $\mathrm{Na}^{+}$-dependent action potentials (Acuna-Goycolea et al., 2008).

We hypothesize that the dendritic region of thalamic interneurons operates in two different regimes, one local and one global. The local processing mode is characterized by release of GABAergic vesicles without the initiation of action potentials in the interneuron and occurs in response to local increases in $\left[\mathrm{Ca}^{2+}\right]_{\mathrm{i}}$ resulting from synaptic potentials and the local dendritic ionic currents that they initiate. The global processing mode occurs whenever an action potential is initiated, presumably in the axon initial segment, which then propagates forward throughout the axonal arbor and backpropagates rapidly throughout dendritic arbors, resulting in the rapid and nearly simultaneous release of GABAergic vesicles from a cloud formed by dendritic and axonal presynaptic terminals of the interneuron. The robust propagation of action potentials throughout the dendritic arbor, where they cause rapid increases in $\left[\mathrm{Ca}^{2+}\right]_{\mathrm{i}}$ (Acuna-Goycolea et al., 2008), does not support the hypothesis, based upon passive models, that thalamic interneuron dendrites are unaffected by somatic/axonal action potentials (Bloomfield and Sherman, 1989). Rather, our results agree with those based upon $\mathrm{Ca}^{2+}$ imaging studies (Acuna-Goycolea et al., 2008): Na/K action potentials invade the entire neuron, from axon to dendrite.

Excitatory synaptic inputs to thalamic interneurons arrive onto the following three broad categories of the soma-dendrite axis: (1) the soma and nearby dendritic trunks; (2) the dendritic knob-like structures that are attached to the dendrite, often through fine processes; and (3) dendritic regions outside the fine, filiform appendages (Hamos et al., 1985; Pape and McCormick, 1995; Godwin et al., 1996; Erișir et al., 1997a; Cox and Sherman, 2000). The functional effects of excitation arriving in each of these three compartments may be considerably different from the others. In rodents, the axon of interneurons (if present) typically arises from a dendrite within $\sim 20-50 \mu \mathrm{m}$ of the soma (Rafols and Valverde, 1973; Perreault et al., 2003). Our VSD experiments indicate that action potentials entering a dendritic branch do so from either the somatic or proximal dendritic region $(<50 \mu \mathrm{m})$. This result is consistent with action potentials being initiated in the axon initial segment, as in other types of neurons (Shu et al., 2007; Kole and Stewart, 2008; Kole et al., 2008; Yu et al., 2008; Hu et al., 2010), followed by propagation throughout the axonal/ dendritic arbor. Synaptic inputs to the soma and proximal dendrite will have a potent influence over the generation of action potentials, owing to their proximity to the axon initial segment. In contrast, inputs to the fine filiform appendages, which, in the LGNd, are typically postsynaptic to retinogeniculate inputs and presynaptic to thalamocortical dendrites, are expected to have a markedly reduced influence upon action potential initiation. It may require the simultaneous activation of several of these to initiate an action potential in the axo/somatic region. Rather, it is likely that activation of retinal synaptic inputs to these electrically remote dendritic locations will result in release of GABAergic vesicles locally, in the absence of the initiation of an action potential by the interneuron (Cox and Sherman, 2000). This is particularly true owing to the conductance mismatch for current flow from the fine filiform appendages into the parent dendrite. It should be noted however that no such conductance mismatch exists in the opposite direction: the parent dendrite is likely to generate sufficient current to fully invade the appendages with each action potential (Rall, 1977). Finally, the excitatory synapses that are positioned on the dendrite proper, outside the fine filiform appendages, such as those arriving from the cerebral cortex (Dubin and Cleland, 1977), will have the opportunity to influence both the action potential activity of the neuron, as well as the dendritic release of GABA from local dendritic sites. In this manner, these GABAergic interneurons may play multiple roles in the precise timing and gating of information flow through the thalamus.

\section{References}

Abraham NM, Egger V, Shimshek DR, Renden R, Fukunaga I, Sprengel R, Seeburg PH, Klugmann M, Margrie TW, Schaefer AT, Kuner T (2010) Synaptic inhibition in the olfactory bulb accelerates odor discrimination in mice. Neuron 65: 399-411.

Acuna-Goycolea C, Brenowitz SD, Regehr WG (2008) Active dendritic conductances dynamically regulate GABA release from thalamic interneurons. Neuron 57:420-431.

Andersen P, Soleng AF, Raastad M (2000) The hippocampal lamella hypothesis revisited. Brain Res 886:165-171.

Antic SD (2003) Action potentials in basal and oblique dendrites of rat neocortical pyramidal neurons. J Physiol 550:35-50.

Berardi N, Morrone MC (1984) The role of gamma-aminobutyric acid mediated inhibition in the response properties of cat lateral geniculate nucleus neurones. J Physiol 357:505-523.

Blitz DM, Regehr WG (2005) Timing and specificity of feed-forward inhibition within the LGN. Neuron 45:917-928.

Bloomfield SA, Sherman SM (1989) Dendritic current flow in relay cells and interneurons of the cat's lateral geniculate nucleus. Proc Natl Acad Sci U S A 86:3911-3914.

Blunck R, Chanda B, Bezanilla F (2005) Nano to micro-fluorescence measurements of electric fields in molecules and genetically specified neurons. J Membr Biol 208:91-102.

Briska AM, Uhlrich DJ, Lytton WW (2003) Computer model of passive signal integration based on whole-cell in vitro studies of rat lateral geniculate nucleus. Eur J Neurosci 17:1531-1541.

Canepari M, Djurisic M, Zecevic D (2007) Dendritic signals from rat hippocampal CA1 pyramidal neurons during coincident pre- and postsynaptic activity: a combined voltage- and calcium-imaging study. J Physiol 580:463-484. 
Carnevale NT, Hines ML (2006) The NEURON book. Cambridge: Cambridge UP.

Christie JM, Westbrook GL (2003) Regulation of backpropagating action potentials in mitral cell lateral dendrites by A-type potassium currents. J Neurophysiol 89:2466-2472.

Cox CL, Sherman SM (2000) Control of dendritic outputs of inhibitory interneurons in the lateral geniculate nucleus. Neuron 27:597-610.

Debanne D, Campanac E, Bialowas A, Carlier E, Alcaraz G (2011) Axon physiology. Physiol Rev 91:555-602.

Djurisic M, Antic S, Chen WR, Zecevic D (2004) Voltage imaging from dendrites of mitral cells: EPSP attenuation and spike trigger zones. J Neurosci 24:6703-6714.

Dubin MW, Cleland BG (1977) Organization of visual inputs to interneurons of lateral geniculate nucleus of the cat. J Neurophysiol 40:410-427.

Erişir A, Van Horn SC, Bickford ME, Sherman SM (1997a) Immunocytochemistry and distribution of parabrachial terminals in the lateral geniculate nucleus of the cat: a comparison with corticogeniculate terminals. J Comp Neurol 377:535-549.

Erişir A, Van Horn SC, Sherman SM (1997b) Relative numbers of cortical and brainstem inputs to the lateral geniculate nucleus. Proc Natl Acad Sci U S A 94:1517-1520.

Errington AC, Di Giovanni G, Crunelli V, Cope DW (2011) mGluR control of interneuron output regulates feedforward tonic $\mathrm{GABA}_{\mathrm{A}}$ inhibition in the visual thalamus. J Neurosci 31:8669-8680.

Famiglietti EV Jr (1970) Dendro-dendritic synapses in the lateral geniculate nucleus of the cat. Brain Res 20:181-191.

Famiglietti EV Jr, Peters A (1972) The synaptic glomerulus and the intrinsic neuron in the dorsal lateral geniculate nucleus of the cat. J Comp Neurol 144:285-334.

Foust A, Popovic M, Zecevic D, McCormick DA (2010) Action potentials initiate in the axon initial segment and propagate through axon collaterals reliably in cerebellar Purkinje neurons. J Neurosci 30:6891-6902.

Godwin DW, Van Horn SC, Eriir A, Sesma M, Romano C, Sherman SM (1996) Ultrastructural localization suggests that retinal and cortical inputs access different metabotropic glutamate receptors in the lateral geniculate nucleus. J Neurosci 16:8181-8192.

Govindaiah G, Cox CL (2004) Synaptic activation of metabotropic glutamate receptors regulates dendritic outputs of thalamic interneurons. Neuron 41:611-623.

Govindaiah G, Cox CL (2006) Metabotropic glutamate receptors differentially regulate GABAergic inhibition in thalamus. J Neurosci 26:13443-13453.

Grinvald A, Salzberg BM, Lev-Ram V, Hildesheim R (1987) Optical recording of synaptic potentials from processes of single neurons using intracellular potentiometric dyes. Biophys J 51:643-651.

Grubb MS, Thompson ID (2003) Quantitative characterization of visual response properties in the mouse dorsal lateral geniculate nucleus. J Neurophysiol 90:3594-3607.

Grubb MS, Thompson ID (2005) Visual response properties of burst and tonic firing in the moise dorsal lateral geniculate nucleus. J Neurophysiol 93:3224-3247.

Guillery RW, Sherman SM (2002) Thalamic relay functions and their role in corticocortical communication: generalizations from the visual system. Neuron 33:163-175.

Hamos JE, Van Horn SC, Raczkowski D, Uhlrich DJ, Sherman SM (1985) Synaptic connectivity of a local circuit neurone in lateral geniculate nucleus of the cat. Nature 317:618-621.

Häusser M, Stuart G, Racca C, Sakmann B (1995) Axonal initiation and active dendritic propagation of action potentials in substantia nigra neurons. Neuron 15:637-647.

Hoffman DA, Magee JC, Colbert CM, Johnston D (1997) K+ channel regulation of signal propagation in dendrites of hippocampal pyramidal neurons. Nature 387:869-875.

Holthoff K, Zecevic D, Konnerth A (2010) Rapid time course of action potentials in spines and remote dendrites of mouse visual cortex neurons. J Physiol 588:1085-1096.

Hu H, Martina M, Jonas P (2010) Dendritic mechanisms underlying rapid synaptic activation of fast-spiking hippocampal interneurons. Science 327:52-58.

Isaacson JS (2001) Mechanisms governing dendritic gamma-aminobutyric acid (GABA) release in the rat olfactory bulb. Proc Natl Acad Sci U S A 98:337-342.
Isaacson JS, Strowbridge BW (1998) Olfactory reciprocal synapses: dendritic signaling in the CNS. Neuron 20:749-761.

Johnston D, Christie BR, Frick A, Gray R, Hoffman DA, Schexnader LK, Watanabe S, Yuan LL (2003) Active dendrites, potassium channels, and synaptic plasticity. Philos Trans R Soc Lond B 358:667-674.

Kennedy MJ, Ehlers MD (2011) Mechanisms and function of dendritic exocytosis. Neuron 69:856-875.

Khaliq ZM, Raman IM (2006) Relative contributions of axonal and somatic $\mathrm{Na}$ channels to action potential initiation in cerebellar Purkinje neurons. J Neurosci 26:1935-1944.

Kole MH, Stuart GJ (2008) Is action potential threshold lowest in the axon? Nat Neurosci 11:1253-1255.

Kole MH, Ilschner SU, Kampa BM, Williams SR, Ruben PC, Stuart GJ (2008) Action potential generation requires a high sodium channel density in the axon initial segment. Nat Neurosci 11:178-186.

Kress GJ, Dowling MJ, Meeks JP, Mennerick S (2008) High threshold, proximal initiation, and slow conduction velocity of action potentials in dentate granule neuron mossy fibers. J Neurophysiol 100:281-291.

Ledergerber D, Larkum ME (2010) Properties of layer 6 pyramidal neuron apical dendrites. J Neurosci 30:13031-13044.

Mainen ZF, Joerges J, Huguenard JR, Sejnowski TJ (1995) A model of spike initiation in neocortical pyramidal neurons. Neuron 15:1427-1439.

Martina M, Vida I, Jonas P (2000) Distal initiation and active propagation of action potentials in interneuron dendrites. Science 287:295-300.

McCormick DA, Huguenard JR (1992) A model of the electrophysiological properties of thalamocortical relay neurons. J Neurophysiol 68:1384-1400

Meeks JP, Mennerick S (2007) Action potential initiation and propagation in CA3 pyramidal axons. J Neurophysiol 97:3460-3472.

Migliore M, Shepherd GM (2002) Emerging rules for the distributions of active dendritic conductances. Nat Rev Neurosci 3:362-370.

Montero VM (1986) Localization of gamma-aminobutyric acid (GABA) in type 3 cells and demonstration of their source to F2 terminals in the cat lateral geniculate nucleus: a Golgi-electron-microscopic GABAimmunocytochemical study. J Comp Neurol 254:228-245.

Nevian T, Larkum ME, Polsky A, Schiller J (2007) Properties of basal dendrites of layer 5 pyramidal neurons: a direct patch-clamp recording study. Nat Neurosci 10:206-214.

Palmer LM, Clark BA, Gründemann J, Roth A, Stuart GJ, Häusser M (2010) Initiation of simple and complex spikes in cerebellar Purkinje cells. J Physiol 588:1709-1717.

Pape HC, McCormick DA (1995) Electrophysiological and pharmacological properties of interneurons on the cat dorsal lateral geniculate nucleus. Neuroscience 68:1105-1125.

Perreault MC, Qin Y, Heggelund P, Zhu JJ (2003) Postnatal development of GABAergic signalling in the rat lateral geniculate nucleus: presynaptic dendritic mechanisms. J Physiol 546:137-148.

Popovic MA, Foust AJ, McCormick DA, Zecevic D (2011) The spatiotemporal characteristics of action potential initiation in layer 5 pyramidal neurons: a voltage-imaging study. J Physiol 589:4167-4187.

Rafols JA, Valverde F (1973) The structure of the dorsal lateral geniculate nucleus in the mouse. A Golgi and electron microscopic study. J Comp Neurol 150:303-332.

Rall W (1977) Core conductor theory and cable properties of neurons. In: Handbook of physiology, cellular biology of neurons (Kandel ER, Brookhardt JM, Mountcastle VM, eds), pp 39-97. Bethesda, MD: American Physiological Society.

Rothman JS, Manis PB (2003) Kinetic analyses of three distinct potassium conductances in ventral cochlear nucleus neurons. J Neurophysiol 89:3083-3096.

Salzberg BM (1983) Optical recording of electrical activity in neurons using molecular probes. In: Current methods in cellular neurobiology (Barker JL, McKelvy JF, eds), pp 139-187. New York: Wiley.

Salzberg BM, Obaid AL, Bezanilla F (1993) Microsecond response of a voltage-sensitive merocyanine dye: fast voltage-clamp measurements of squid giant axon. Jpn J Physiol 43 [Suppl 1]:S37-S41.

Scheetz AJ, Dubin MW (1994) Cytochemical polarity in lateral geniculate interneurons. Brain Res 639:181-192.

Schmidt-Hieber C, Jonas P, Bischofberger J (2008) Action potential initiation and propagation in hippocampal mossy fibre axons. J Physiol 586:1849-1857.

Sherman SM, Friedlander MJ (1988) Identification of X versus Y properties 
for interneurons in the A-laminae of the cat's lateral geniculate nucleus. Exp Brain Res 73:384-392.

Shu Y, Duque A, Yu Y, Haider B, McCormick DA (2007) Properties of action-potential initiation in neocortical pyramidal cells: evidence from whole cell axon recordings. J Neurophysiol 97:746-760.

Sillito AM, Kemp JA (1983) The influence of GABAergic inhibitory processes on the receptive field structure of $\mathrm{X}$ and $\mathrm{Y}$ cells in cat dorsal lateral geniculate nucleus (dLGN). Brain Res 277:63-77.

Stuart G, Häusser M (1994) Initiation and spread of sodium action potentials in cerebellar Purkinje cells. Neuron 13:703-712.

Stuart G, Schiller J, Sakmann B (1997) Action potential initiation and propagation in rat neocortical pyramidal neurons. J Physiol 505:617-632.
Williams SR, Stuart GJ (2000) Action potential backpropagation and somato-dendritic distribution of ion channels in thalamocortical neurons. J Neurosci 20:1307-1317.

Yu Y, Shu Y, McCormick DA (2008) Cortical action potential backpropagation explains spike threshold variability and rapid-onset kinetics. J Neurosci 28:7260-7272.

Zelles T, Boyd JD, Hardy AB, Delaney KR (2006) Branch-specific $\mathrm{Ca}^{2+}$ influx from $\mathrm{Na}^{+}$-dependent dendritic spikes in olfactory granule cells. J Neurosci 26:30-40.

Zhou WL, Yan P, Wuskell JP, Loew LM, Antic SD (2008) Dynamics of action potential backpropagation in basal dendrites of prefrontal cortical pyramidal neurons. Eur J Neurosci 27:923-936. 